Document downloaded from:

http://hdl.handle.net/10251/49874

This paper must be cited as:

Martí Calatayud, MC.; Buzzi, DC.; García Gabaldón, M.; Bernardes, AM.; Tenório, JAS.; Pérez Herranz, V. (2014). Ion transport through homogeneous and heterogeneous ionexchange membranes in single salt and multicomponent electrolyte solutions. Journal of Membrane Science. 466:45-57. doi:10.1016/j.memsci.2014.04.033.

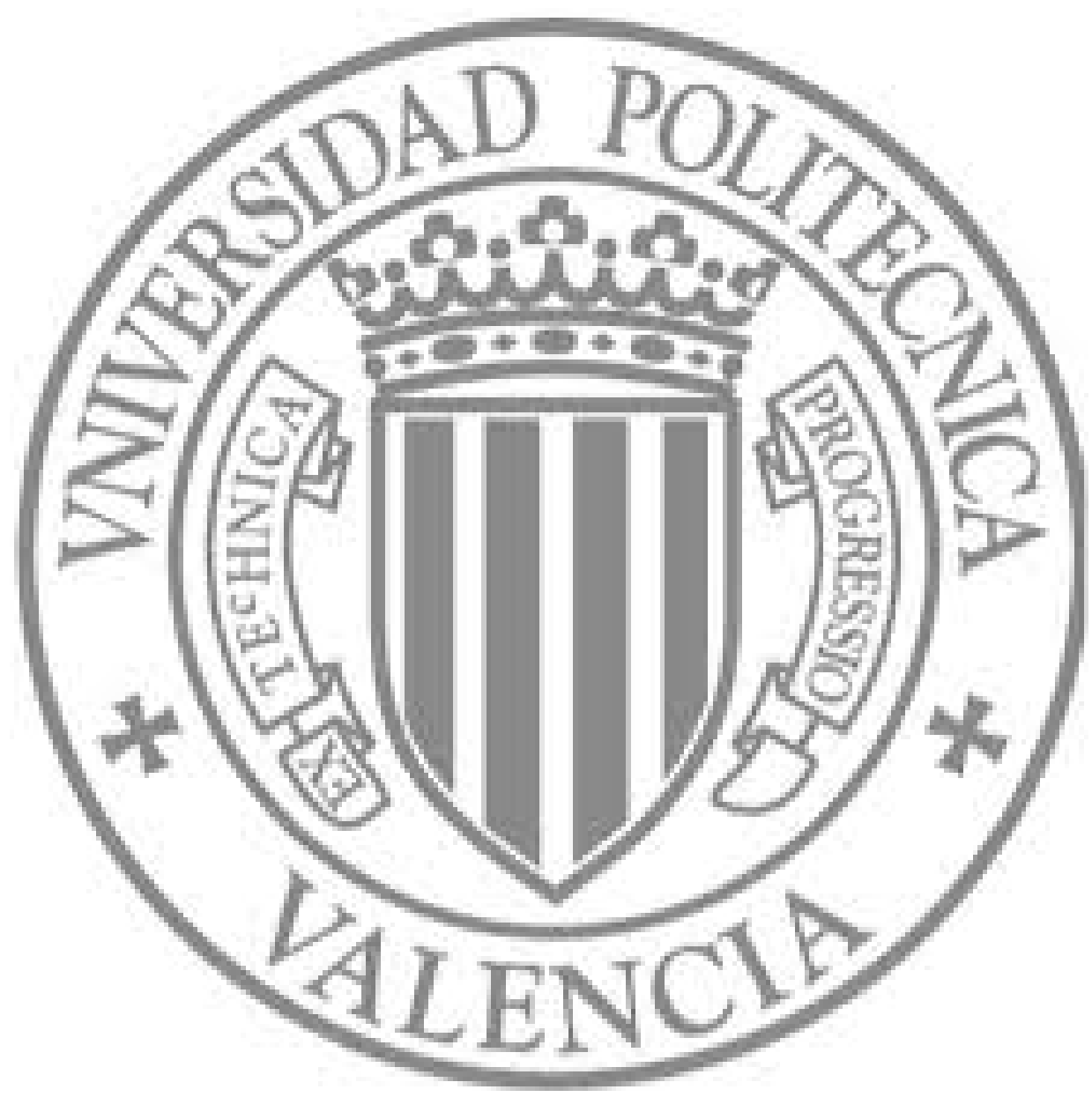

The final publication is available at

http://dx.doi.org/10.1016/j.memsci.2014.04.033

Copyright Elsevier 


\title{
Ion transport through homogeneous and heterogeneous ion-exchange membranes in single salt and multicomponent electrolyte solutions
}

\author{
M.C. Martí-Calatayud ${ }^{\mathrm{a}}$, D.C. Buzzi ${ }^{\mathrm{a}, \mathrm{b}, \mathrm{c}}$, M. García-Gabaldón ${ }^{\mathrm{a}}$, A.M. Bernardes ${ }^{\mathrm{c}}$, \\ J.A.S. Tenório ${ }^{\mathrm{b}}$, V. Pérez-Herranz ${ }^{\mathrm{a}}{ }^{, *}$ \\ a IEC Group, Departament d'Enginyeria Quimica i Nuclear, Universitat Politècnica de València, Camí de \\ Vera s/n, 46022, València, P.O. Box 22012, E-46071, Spain \\ ${ }^{\mathrm{b}}$ Department of Materials and Metallurgical Engineering, Universidade de São Paulo, Av. Prof. Mello \\ Moraes 2463, 05508-030, São Paulo, SP, Brazil \\ c Department of Materials Engineering, Universidade do Rio Grande do Sul, Av. Bento Gonçalves 9500, \\ 91509-900, Porto Alegre, RS, Brazil \\ *Corresponding author: Tel.:+34 963877632; Fax: +34 963867639. \\ E-mail addresses: vperez@iqn.upv.es (V. Pérez-Herranz), \\ mamarc13@upvnet.upv.es (M.C. Martí-Calatayud), danicbuzzi@gmail.com (D.C. \\ Buzzi)
}

Keywords: ion-exchange membranes, electrodialysis, concentration polarization, membrane heterogeneity, competitive ion transport

\begin{abstract}
The increasing demand for clean industrial processes has intensified the use of electrodialysis in the treatment of metal containing effluents and encourages the investigation of the different phenomena involved in the transport of metal ions through cation-exchange membranes. Ion sorption, chronopotentiometric and current-voltage characteristics have been obtained to characterize the transport of sodium and iron through homogeneous and heterogeneous cation-exchange membranes. The heterogeneous membranes having a broader pore size distribution showed increased electrical resistances with solutions of trivalent iron, which may be caused by the blockage of the smallest pores by multivalent ions. However, for both types of membranes an unexpected decrease of the electrical resistance with increasing current densities was verified with concentrated solutions of $\mathrm{Fe}_{2}\left(\mathrm{SO}_{4}\right)_{3}$. This behavior was explained to be a consequence of the dissociation of $\mathrm{FeSO}_{4}{ }^{+}$ions into more conductive
\end{abstract}


$\mathrm{Fe}^{3+}$ and $\mathrm{SO}_{4}{ }^{2-}$ ions as the depleting solution layer becomes diluted. When tested with multicomponent mixtures, the homogeneous perfluorosulfonic membranes show an increased preference for $\mathrm{Na}^{+}$ions at low current densities and, once $\mathrm{Na}^{+}$ions are depleted from the membrane surface $\mathrm{Fe}^{3+}$ ions are transported preferentially at higher current densities. On the contrary, both $\mathrm{Na}^{+}$ions and $\mathrm{Fe}$ (III) species are responsible for the ion transport through the heterogeneous membranes within the ohmic regime of currents. 


\section{Introduction}

In the recent time, the number of applications that use ion-exchange membranes has increased considerably. Among others, the use of ion-exchange membranes in separation processes and fuel cells stands out owing to the important environmental and economical benefits that they can bring to the society [1,2]. In the field of wastewater treatment, ion-exchange membranes are applied in electrodialysis cells in order to remove ionic contaminants from aqueous effluents. The treatment of industrial wastewaters is a potential application of electrodialysis because it can contribute to reduce the discharge of hazardous ions to the environment while allowing the recovery of metals whose price is increasing.

One of the effluents that can be treated by electrodialysis is acid mine drainage (AMD) produced in coal extracting sites. AMD solutions are generated as a result of the oxidation of piryte $\left(\mathrm{FeS}_{2}\right)$. These solutions mainly contain sulfuric acid and trivalent iron along with other metals. To date the most established technology to treat AMD is the addition of limes to neutralize the drainage and precipitate the metals. As a result, a ferruginous solid waste to be disposed of in landfills is produced. Therefore, liming requires the addition of reagents and disposal space for the resulting waste [3]. In this context, electrodialysis is an alternative treatment process that can be applied to reclaim large volumes of water [4], and produce valuable by-products from AMD, such as sulfuric acid [5]. Furthermore, with the use of this technology the addition of chemicals and the generation of solid wastes are minimized.

The properties of ion-exchange membranes determine to a great extent the performance of electrodialysis cells. These membranes have fixed charges attached to their structure that, under the imposition of an electric field, allow the permeation of ions with opposite charge and reject ions with the same charge sign. Ion-exchange membranes are required to combine low electrical resistance and good permselectivity in order to achieve a fast separation of ions with low energy consumptions. In addition, they should exhibit good mechanical and chemical durability at a reasonable cost. Some efforts have been made to produce ion-exchange membranes based on ceramic materials which can resist the extreme $\mathrm{pH}$ values, oxidizing or radioactive conditions of industrial environments [6]. However, these membranes are still under development stage and the 
use of polymeric membranes is broader. Polymeric membranes are commonly classified according to their structure into homogeneous and heterogeneous. Homogeneous membranes are characterized by having a uniform distribution of ion exchange groups attached to their polymer backbone. Within this group, those based on perflurosulfonic polymers are considered as a reference due to their excellent chemical durability and electrochemical properties, what makes them suitable for a variety of applications. Alternatively, heterogeneous ion-exchange membranes have a more disperse distribution of ion exchange sites. These membranes possess good mechanical stability and are produced at a more reasonable cost. Moreover, their electrochemical properties can be improved by optimizing the loading of ion-exchange particles $[2,7,8]$.

The strong relationship existing between the structure of ion-exchange membranes and their electrochemical and transport properties has been the object of several investigations [9-12]. However, these studies are often conducted with single salt solutions of monovalent ions, while most industrial effluents, such as AMD, are composed of mixtures of ions where the presence of transition metals is common. The differences in charge and shape between ions could determine their rates of transport through the membranes and the nature of the ionic species present in the mixture, hence affecting the electrical resistance of the membranes. In addition, the degree of heterogeneity of ion-exchange membranes has been reported to affect the development of concentration polarization in the vicinity of their surfaces [13,14]. Little is known, however, about the influence of the membrane structure on the competitive ion transport in multi-ionic mixtures treated by electrodialysis. In addition, the investigation of the development of concentration polarization phemomena in such membrane/electrolyte systems could have interesting implications for emerging applications of electrodialysis.

Therefore, in the present study we aim to investigate the effects that the structure of ionexchange membranes could have on the competitive ion transport in electrodialysis cells. For this purpose, different membrane/electrolyte systems have been considered. To carry out the different experiments, various synthetic solutions were prepared by taking the composition of AMD solutions as a reference. The structures of a heterogeneous and a homogeneous cation-exchange membrane were first compared and the equilibrium ion partitioning of the membranes immersed in multicomponent electrolyte solutions was evaluated. Then, the dynamics of the ionic transport through 
the membranes under the effect of an applied electric field was studied in single salt solutions of both mono- and multivalent metals and, in multicomponent ionic solutions. 


\section{Materials and methods}

\subsection{Ion-exchange membranes}

Two different cation-exchange membranes were used in the present study. Nafion 117 (Du Pont) was used as homogeneous membrane. This membrane has a fluorocarbonbased polymer matrix with sulfonic acid groups attached to the polymer backbone. Nafion 117 has an ion exchange capacity of $0.90 \mathrm{meq} / \mathrm{g}$ of dry membrane and a typical thickness of $183 \mu \mathrm{m}$. HDX 100 (supplied by Hidrodex) was used as heterogeneous cation-exchange membrane. HDX 100 also presents sulfonic acid groups as fixed ion exchange sites. The heterogeneous structure of the HDX membrane has reinforcing fabrics at both its sides to increase the mechanical resistance of the membrane. HDX 100 has an ion exchange capacity of $2 \mathrm{meq} / \mathrm{g}$ of dry membrane and a characteristic thickness of $450 \mu \mathrm{m}$.

HDX 200 (supplied by Hydrodex) was used as the auxiliary anion-exchange membrane for the chronopotentiometric experiments. It has similar characteristics to HDX 100, but the cationic fixed groups of these membranes are quaternary amines.

\subsection{Acid mine drainage and synthetic solutions}

The chemical characterization of various AMD samples collected from different locations of a carboniferous area in Brazil was obtained from a previous work [4]. The composition of AMD varies significantly depending on the source from which the sample is taken. The composition of the AMD solutions considered for the present study is shown in Table 1

The highest concentration in multivalent metals is that of trivalent iron, and the presence of $\mathrm{SO}_{4}{ }^{2-}$ ions is predominating over other anions. Moreover, in order to evaluate the competitive transport of different cations through the membranes, the presence of $\mathrm{Na}^{+}$ions was also considered, since it is the metal having the second largest concentration in the AMD solutions. The concentration of the other ions present in AMD solutions is significantly lower and was neglected for the sake of simplicity. Accordingly, we prepared synthetic mixtures of $0.02 \mathrm{M} \mathrm{Fe}_{2}\left(\mathrm{SO}_{4}\right)_{3}$ and $0.01 \mathrm{M} \mathrm{Na} \mathrm{NO}_{4}$ 
(Panreac $\left.{ }^{\circledR}\right)$, which have a similar concentration to that determined in the AMD solutions. The solutions were prepared with distilled water and were taken as a reference for the present study.

Moreover, in order to elucidate the differences between the transport of alkaline and transition metal ions, the electrochemical behavior of the membranes immersed in single salt solutions of $\mathrm{Na}_{2} \mathrm{SO}_{4}$ or $\mathrm{Fe}_{2}\left(\mathrm{SO}_{4}\right)_{3}$ was also investigated. Finally, the present study is also extended to equimolar solutions of $\mathrm{Na}(\mathrm{I})$ and $\mathrm{Fe}(\mathrm{III})$.

\subsection{Visualization of the membrane structure}

The membrane structure was visualized using an electron scanning microscope (JEOL JSM-3600). The membrane samples used for the SEM analysis were prepared by freezing the dry membranes in liquid nitrogen and breaking them to produce a cross section. Then, micrographs of the surface and cross sections of each membrane were obtained.

\subsection{Ion uptake experiments}

Membrane stripes of the same size were cut and equilibrated in different electrolyte solutions during $24 \mathrm{~h}$. The electrolyte present at the surface of the membranes was removed with blotting paper and the counter-ions equilibrated with the fixed ion exchange sites of the membranes were extracted by immersing the membrane in $1 \mathrm{M}$ $\mathrm{H}_{2} \mathrm{SO}_{4}$ for other $24 \mathrm{~h}$ under stirring conditions. Finally, the metallic content of the $\mathrm{H}_{2} \mathrm{SO}_{4}$ solutions was measured by atomic absorption spectrometry (Perkin Elmer, Model AAnalyst 100). The concentration of iron was measured by atomic absorption with a lamp current of $5 \mathrm{~mA}$ and a wave length of $248.3 \mathrm{~nm}$ and the concentration of sodium was measured by atomic emission at a wave length of $589.0 \mathrm{~nm}$.

\subsection{Chronopotentiometric experiments}

Chronopotentiometric experiments were conducted to characterize the dynamics of the ionic transport through the membranes. The membranes were first equilibrated for at least $24 \mathrm{~h}$ with the solutions to be used subsequently. The experimental setup was composed of three compartments with a volume capacity of $130 \mathrm{~mL}$ between which the anion- and the cation-exchange membranes were clamped (Fig. 1). A 
potentiostat/galvanostat (Autolab®, PGSTAT 20) was used to apply the current pulses between the working and the counter electrode, which were made of graphite. Two $\mathrm{Ag} / \mathrm{AgCl}$ reference electrodes immersed in Luggin capillaries were installed at both sides of the membrane under study and were used to measure the voltage drop through the membrane system $\left(\mathrm{U}_{\mathrm{m}}\right)$. Therefore, $\mathrm{U}_{\mathrm{m}}$ includes the voltage contribution of the membrane itself and that of the two adjoining solution layers. The effective membrane area was $3.52 \mathrm{~cm}^{2}$. The same solution was introduced in the three compartments so that to study the effect of the applied current on the symmetrical membrane/electrolyte system. The experiments were conducted at room temperature $\left(25^{\circ} \mathrm{C}\right)$. Each current pulse was applied during 300 seconds. Then, the current was interrupted and the relaxation process of the system was registered. Moreover, the current-voltage curves of each membrane/electrolyte system were obtained by plotting the steady value of $U_{m}$ registered in the chronopotentiograms against their corresponding value of applied current density. 


\section{Results and discussion}

\subsection{Characterization of the membrane structure}

Knowledge on the morphology and internal structure of ion-exchange membranes is crucial in order to understand the manner in which the ionic transfer occurs through different conducting membranes. The surface and cross section micrographs of the investigated cation-exchange membranes are presented in Fig. 2. The differences between the structures of Nafion 117 and HDX 100 are evident from the SEM pictures. While the surface and cross section of Nafion 117 (Fig. 2 (a) and (b)) show a dense and uniform conformation (exept for the fractures originated during the vacuum drying of the samples for the SEM characterization), the presence of agglomerates of ionexchange particles dispersed through the HDX 100 membrane can be clearly observed in Fig. 2 (c) - (f). This difference may imply a higher fraction of non-conducting regions in the HDX 100 membrane. Moreover, the two reinforcing fabrics enclosing the structure of the HDX 100 membrane can be clearly seen in Fig. 2(d).

Apart from the membrane morphology, the thickness of ion-exchange membranes is another factor which has to be optimized to simultaneously minimize the electrical resistance and ensure good mechanical and chemical stability. The high chemical and mechanical stability of Nafion 117 is due to its fluoro-carbon polymeric backbone. On the other hand, the larger thickness of HDX 100 together with the presence of reinforcing fibers possibly contributes to increase the mechanical resistance of these membranes.

Moreover, in addition to the visualization of the membrane structure with the SEM images, which provide a qualitative perception of the membrane morphology, the degree of heterogeneity of ion-exchange membranes can also be determined. In this respect, even the so-called homogeneous membranes (such as Nafion) are known to present non-conducting regions at the submicroscopic scale [15], which has motivated the development of several models to describe their structure $[9,16,17]$. Choi et al. also developed a method to estimate the fraction of conducting regions $(\varepsilon)$ of ion-exchange membranes by means of chronopotentiometry [12]. This method can be used to compare the heterogeneity of membranes with different morphologies, hence being 
suitable to compare the HDX 100 and the Nafion 117 membranes used in the present study. When a direct current is applied through a membrane system and the concentration polarization phenomena is developed up to the point that the concentration of counter-ions at the membrane depleting surface approaches zero, a sharp increase in $U_{m}$ is registered. The time at which the steepest increase in the voltage drop takes place is known as the transition time, $\tau$. Choi et al. modified the Sand's equation, which relates the transition time with the applied current density (i), in order to include the effect of the membrane heterogeneity [12]:

$$
\tau=\frac{\varepsilon^{2} \pi \cdot D}{4} \cdot\left(\frac{z \cdot F}{T_{j}-t_{j}}\right)^{2}\left(\frac{c_{0}}{i}\right)^{2}
$$

In Eq.(1) D is the salt diffusion coefficient, $\mathrm{c}_{0}$ is the electrolyte concentration, $\mathrm{F}$ is the Faraday's constant, $z$ the valence of the counter-ion and, $T_{j}$ and $t_{j}$ are the transport number of the counter-ion $\mathrm{j}$ in the membrane and the solution phase, respectively. Therefore, if all the parameters of Eq. (1) are known, the $\varepsilon$ values can be determined from the modified Sand's equation. The $\varepsilon$ values of the Nafion 117 and the HDX 100 membrane were calculated from chronopotentiometric results obtained with $0.05 \mathrm{M}$ $\mathrm{NaCl}$. For this calculation we used the following parameters: $\mathrm{D}=1.61 \cdot 10^{-5} \mathrm{~cm}^{2} \cdot \mathrm{s}^{-1}, \mathrm{z}=$ $1, \mathrm{t}_{\mathrm{j}}=0.396, \mathrm{~T}_{\mathrm{j}}^{\text {Nafion117 }}=0.98$ (calculated with the e.m.f. method), and $\mathrm{T}_{\mathrm{j}}^{\mathrm{HDX100}}=0.9$ (provided by the manufacturer). The $\varepsilon$ values obtained for the Nafion 117 and the HDX 100 membranes are 0.981 and 0.804 , respectively. These values reflect the distinct degree of heterogeneity of both membranes, as already deduced from the SEM images. Whereas Nafion can be considered as macroscopically homogeneous, the fraction of conducting regions of the HDX 100 membrane is lower, and similar to the $\varepsilon$ values reported for other heterogeneous membranes [12]. The heterogeneity of the HDX 100 membrane stems from the reinforcing fibers, but also from the inert polymer binder, which apart from being impermeable to ions, also complicates the connectivity between different ion-exchange pathways inside the membrane structure. 


\subsection{Ion uptake equilibrium}

The results obtained from the ion uptake experiments are summarized in Fig. 3. Fig. 3(a) shows the concentration of ions equilibrated in the membrane phase $\left(c_{m}\right)$ expressed in mmol per $g$ of dry membrane as a function of the composition of the equilibrating solution. When the membranes are equilibrated with $\mathrm{Na}_{2} \mathrm{SO}_{4}$ solutions, the values of $\mathrm{c}_{\mathrm{m}}$ are almost coincident with the ion-exchange capacity provided by the manufacturers (0.89 meq/g for the Nafion and $2.07 \mathrm{meq} / \mathrm{g}$ for the HDX membrane). On the contrary, the results obtained with solutions containing $\mathrm{Fe}_{2}\left(\mathrm{SO}_{4}\right)_{3}$ reveal that the amount of $\mathrm{Fe}(\mathrm{III})$ bound to the fixed charges is significantly lower. These different results reveal that the multicharged Fe(III) species present inside the membrane phase could be associated with more than one sulfonic fixed ionic groups.

The ratio between the concentrations of metal ions in the membrane phase is compared with its analogous in the equilibrating solutions in Fig. 3(b). The most remarkable conclusion is the confirmation that the affinity of both membranes is stronger for $\mathrm{Fe}^{3+}$ ions than for $\mathrm{Na}^{+}$ions. This result is in agreement with previous literature $[18,19]$, and is probably caused by the higher attractive electrostatic forces existing between the sulfonic acid groups of both membranes and cations of higher charge. However, as the concentration of $\mathrm{Na}^{+}$ions in the electrolyte increases, the ion partition equilibrium of both membranes shows a different evolution. The preference of the HDX 100 membrane for $\mathrm{Fe}^{3+}$ ions is significantly higher than that of Nafion 117. Specifically, when the membranes are equilibrated in equimolar mixtures of sodium and iron, the $[\mathrm{Na}(\mathrm{I})] /[\mathrm{Fe}(\mathrm{III})]$ ratio in the membrane phase is 0.36 for Nafion, whereas it only reaches 0.16 for HDX 100. These results corroborate the important effect of the membrane structure and ion exchange capacity on the affinity of the membranes for ions of different valence. Probably the higher number of ion exchange sites present in the HDX 100 membrane would be responsible for its higher preference for multivalent ions. 


\subsection{Electrochemical characterization of the cation-exchange membranes}

\subsubsection{Behavior of homogeneous and heterogeneous membranes with single salt solutions}

The electrochemical behavior of the membranes was first investigated in single salt solutions of $\mathrm{Na}(\mathrm{I})$ and $\mathrm{Fe}(\mathrm{III})$. The chronopotentiometric response obtained for both membranes with $0.01 \mathrm{M} \mathrm{Na}_{2} \mathrm{SO}_{4}$ is presented in Fig. 4. The shape of the curves is the typical one obtained with binary solutions of monovalent ions. At the beginning of the application of the current pulses $U_{m}$ takes an initial value, which corresponds to the ohmic voltage of the membrane system. Then, for very low current densities the evolution of $U_{m}$ is almost constant with time. However, as the current density is increased, the concentration of $\mathrm{Na}^{+}$ions decreases at the depleting side of the membrane because the membrane is permselective for counter-ions. As a consequence, $U_{m}$ increases with time during the application of the current pulses. If the current density reaches a characteristic value known as the limiting current density $\left(i_{\text {lim }}\right)$, the concentration of $\mathrm{Na}^{+}$ions at the depleting electrolyte/membrane interface approaches zero and a steep increase in $\mathrm{U}_{\mathrm{m}}$ is registered (as denoted by the transition times indicated in Fig. 4(a)). Accordingly, the $i_{\text {lim }}$ defines the transition between the range of currents corresponding to a membrane system with quasi-ohmic behavior, and the range of currents where concentration polarization is intense and the supply of ions to the membrane surface is limited by diffusion. Nevertheless, the supply of ions to the membrane can be again reactivated at an advanced stage of concentration polarization, thus leading to current densities higher than the $i_{\text {lim. }}$. For example, in the present case both membranes show oscillations in $U_{m}$ at the current density of $1.98 \mathrm{~mA} \cdot \mathrm{cm}^{-2}$. These oscillations have been usually attributed to electroconvective vortexes that provide an additional mixing of the depleting boundary layers at current densities far above the $\mathrm{i}_{\text {lim }}$ $[20,21]$.

Despite the similarities observed between the curves obtained for both membranes, some differences can be elucidated from the evolution of $U_{m}$ with time: the increase in $U_{m}$ registered when the $i_{\text {lim }}$ is reached is very fast and acute in the case of Nafion 117 , whereas it is smoother for the HDX 100 membrane. This distinct behavior may be originated by the different degree of heterogeneity of each membrane, as explained in 
previous studies conducted with heterogeneous membranes [14,22]. The even distribution of ion-exchange sites over the polymer backbone of Nafion favors the simultaneous depletion of counter-ions over the entire membrane surface. On the contrary, heterogeneous membranes have a more irregular distribution of ion-exchange sites and a higher fraction of non-conducting regions, which would explain the smoother response obtained for the HDX 100 membrane. Another remarkable difference between the responses of both membranes is the fact that the final values of $U_{m}$ registered for a fixed current density are significantly higher for HDX 100, which indicates that this membrane has a higher electrical resistance.

In the case of $\mathrm{Fe}_{2}\left(\mathrm{SO}_{4}\right)_{3}$ solutions, the chronopotentiometric response of both membranes is different from the typical one observed with $\mathrm{Na}_{2} \mathrm{SO}_{4}$ solutions. At low values of current density (Figs. 5 (a) and (b)), $U_{m}$ reaches a maximum and then decreases with time. The decrease in $U_{m}$ becomes more pronounced as the current density increases, which implies a reduction in the electrical resistance of the membrane system for increasing current densities. This membrane behavior is markedly different from that observed with monovalent cations, where the continuous depletion of counterions near the membranes leads to a gradual increase of the electrical resistance with current density.

The chronopotentiograms obtained for higher values of current density are shown in Fig. 5 (c) and (d). An inflexion point is observed in the curves corresponding to the current densities of $17.14 \mathrm{~mA} \cdot \mathrm{cm}^{-2}$ and $14.45 \mathrm{~mA} \cdot \mathrm{cm}^{-2}$ for Nafion 117 and HDX 100, respectively. As commented above, this characteristic feature is ascribed to the depletion of counter-ions at the diluting side of the membrane when the $i_{\text {lim }}$ has been exceeded. In analogy to the results obtained with $\mathrm{Na}_{2} \mathrm{SO}_{4}$ solutions, the inflexion point is also very sharp for the Nafion 117 membrane and smoother for the HDX 100 membrane. Moreover, in the case of Nafion 117 a second increase of $U_{m}$ takes place at higher current densities (i.e. $17.56 \mathrm{~mA} \cdot \mathrm{cm}^{-2}$ ). This increase is even more acute than the first one and lasts during the course of the current pulse without observing any stabilization in the $U_{m}$ value. The second increase in $U_{m}$ is probably related to the formation of a precipitate layer at the anodic side of the membrane once the $i_{\text {lim }}$ is surpassed, which was visually confirmed at the end of these experiments and is shown in the inset photograph of Fig. 5(c). For the HDX membrane, however, the second 
increase in $U_{m}$ is not observed. Instead of that, $U_{m}$ increases immediately after the current is switched on (for $\mathrm{i} \geq 14.59 \mathrm{~mA} \cdot \mathrm{cm}^{-2}$ ). This different response may indicate the presence in the heterogeneous membrane of some pores more prone to the formation of precipitates where this phenomenon starts from the beginning of the current pulse. The formation of precipitates at the surface of HDX 100 was also confirmed at the end of the experiments. Since this membrane is not transparent, the state of the membrane before and after the formation of precipitates is shown in the inset photographs of Fig. 5(d).

In addition to the response obtained during the application of current, the voltage measurement registered once the current has stopped also provides useful information about the relaxation of the concentration profiles in the membrane system. Specifically, an additional feature is observed for the same currents at which the second inflexion point takes place in the case of Nafion or the anticipated increase in $U_{m}$ is observed for the HDX membrane: once the current is stopped, the voltage drop decreases immediately reaching a plateau value and then is restored slowly to zero. The voltage remaining after switching off the current and the slow restoration of the membrane potential is characteristic of bipolar membranes and has been attributed to the recombination of water dissociation products $[23,24]$. Moreover, this characteristic has also been reported for monopolar membranes when a layer of precipitates is formed at the membrane surface, a quasi-bipolar structure is developed and the dissociation of water is catalyzed by the deposited metal hydroxides $[25,26]$.

In connection with the atypical response observed for both membranes with solutions of $\mathrm{Fe}(\mathrm{III})$, it has to be noted that the shape of the chronopotentiograms obtained in a previous study for the Nafion membrane with solutions of Fe(III) was significantly dependent on the initial salt concentration [25]. Therefore, in order to confirm that this difference is originated from the characteristics of the electrolyte, additional experiments were conducted with $0.001 \mathrm{M} \quad \mathrm{Fe}_{2}\left(\mathrm{SO}_{4}\right)_{3}$. Fig. 6 shows the chronopotentiograms obtained for both membranes, which are very similar to those observed for $\mathrm{Na}_{2} \mathrm{SO}_{4}$ solutions. In this case the chronopotentiograms obtained with HDX 100 show even a smoother response if compared with that of Fig. 4(b), thus confirming the wider pore size distribution and the irregular repartition of ion-exchange sites of the HDX 100 membrane, which in this case is emphasized by the greater size of $\mathrm{Fe}(\mathrm{III})$ species. In addition, the profile of $\mathrm{U}_{\mathrm{m}}$ during the relaxation of both membranes 
when the current ceases is analogous to that observed for $\mathrm{Na}_{2} \mathrm{SO}_{4}$ solutions, and coincides also with the absence of precipitates at the end of the experiments.

In order to elucidate the origin of the different behavior observed for concentrated and diluted $\mathrm{Fe}_{2}\left(\mathrm{SO}_{4}\right)_{3}$ solutions, the concentration of species at the initial equilibrium conditions for all the studied electrolytes was obtained according to the reactions of formation of complex species detailed in the Appendix. The concentrations of the different ionic species are summarized in Table 2. In the case of $0.02 \mathrm{M} \mathrm{Fe}_{2}\left(\mathrm{SO}_{4}\right)_{3}$ solutions the concentration of $\mathrm{Fe}^{3+}$ ions is negligible if compared with that of $\mathrm{FeSO}_{4}{ }^{+}$ ions. On the contrary, the ratio of concentrations $\left[\mathrm{Fe}^{3+}\right] /\left[\mathrm{FeSO}_{4}{ }^{+}\right]$reaches the value of 0.15 for $0.001 \mathrm{M} \mathrm{Fe}_{2}\left(\mathrm{SO}_{4}\right)_{3}$. Therefore, when the cation-exchange membranes immersed in diluted solutions of iron are submitted to an electric field, the more mobile $\mathrm{Fe}^{3+}$ ions are accessible to the membrane surface and can contribute to carry the ionic current through the membranes. On the other hand, for more concentrated solutions and at low polarization levels, the predominance of $\mathrm{FeSO}_{4}{ }^{+}$ions is much higher and the contribution of $\mathrm{Fe}^{3+}$ ions to the ionic transfer through the membranes is less significant.

However, when the concentration polarization is intensified the initial equilibrium conditions can be altered, thus changing the proportion between the ions present in the depleting diffusion boundary layer and, consequently, also the ions being supplied to the membrane surface. In the present case, the initial increase observed in $U_{m}$ appearing immediately after starting the current pulses of Fig. 5(a) may be induced by the decrease in the concentration near the membrane surface of the ions of higher mobility. Specifically, the concentration of cationic species like $\mathrm{Fe}^{3+}$ ions would decrease as they migrate toward the cathodic compartment, whereas the free $\mathrm{SO}_{4}{ }^{2-}$ ions are repelled by the fixed charges of the membranes and migrate toward the anode driven by the applied electric field. Subsequently, as the diffusion boundary layer becomes more diluted, the equilibrium may be displaced toward the formation of $\mathrm{Fe}^{3+}$ and $\mathrm{SO}_{4}{ }^{2-}$ ions from the $\mathrm{FeSO}_{4}{ }^{+}$ions initially present in the solution:

$\mathrm{FeSO}_{4}^{+} \rightleftarrows \mathrm{Fe}^{3+}+\mathrm{SO}_{4}^{2-}$

Therefore, under sufficiently intense polarization conditions, the displacement from the initial equilibrium state in the depleting solution layer implies the enrichment in 
multicharged ions of the membrane region. Both $\mathrm{Fe}^{3+}$ and $\mathrm{SO}_{4}{ }^{2-}$ ions are much more mobile than the monovalent $\mathrm{FeSO}_{4}{ }^{+}$complex ion, as can be deduced from the diffusion coefficients presented in Table 3. Furthermore, the higher mobility and charge of $\mathrm{Fe}^{3+}$ and $\mathrm{SO}_{4}{ }^{2-}$ ions implies an even more pronounced increase in the ionic conductivities (see Table 3), which may confirm the role of these ions on the gradual decrease observed in $U_{m}$ for increasing current densities. In analogy to our results, a similar effect was observed in preceding studies where the electrical conductivity of ionexchange membranes increased as a result of an enrichment of the membrane phase in multicharged ions [27,28]. Hence, the diffusion boundary layers of membrane systems in contact with weak electrolytes can be regarded as a dynamic reaction layer where the displacement of the equilibrium conditions can alter the ionic species being transported through the membranes. A similar approach was adopted in a previous study in order to model the transport of weak acid anions through anion-exchange membranes [29]. A schematic representation of this phenomenon taking place with concentrated solutions of $\mathrm{Fe}_{2}\left(\mathrm{SO}_{4}\right)_{3}$ is depicted in Fig. 7(a).

With regard to the response observed with $0.02 \mathrm{M} \mathrm{Fe}_{2}\left(\mathrm{SO}_{4}\right)_{3}$ at overlimiting currents (Fig. 5(c) and (d)), the almost vertical increase of $U_{m}$ obtained for the Nafion 117 membrane at the current density of $17.14 \mathrm{~mA} \cdot \mathrm{cm}^{-2}$ indicates the simultaneous depletion of $\mathrm{Fe}^{3+}$ ions over the effective area of the membrane. On the other hand, $\mathrm{U}_{\mathrm{m}}$ increases gradually for the HDX 100 membrane at the current density of $14.45 \mathrm{~mA} \cdot \mathrm{cm}^{-2}$ and this increase is not reproducible for higher current densities. For the HDX membrane, the depletion of ions occurs faster near the more conducting regions whereas it takes place at higher current densities and larger times in the less conducting regions. This irregular development of concentration gradients would imply the immediate formation of precipitates in the smallest and more conducting pores of the HDX membrane when overlimiting currents are applied. As this occurs, the pores being blocked by the precipitates turn into non-conductive regions, thus leading to the fast increase of $U_{m}$ observed from the beginning of the current pulses in Fig. 5(d).

In addition to the chronopotentiometric curves, the current-voltage characteristics are also a useful tool to understand the behaviour of the membrane/electrolyte systems at different ranges of currents. The current-voltage curves of the different systems studied 
are presented in Fig. 8. The current-voltage curves obtained for diluted electrolytes (Fig. $8(a))$ have three characteristic regions:

(i) The quasi-ohmic region characteristic of low current densities $\left(i<i_{\text {lim }}\right)$, where the current increases almost linearly with $U_{\mathrm{m}}$. The ohmic electrical resistance of the membrane system $\left(\mathrm{R}_{1}\right)$ can be calculated from the inverse of the slope of this region.

(ii) The region of limiting current density $\left(i \approx \mathrm{i}_{\text {lim }}\right)$, which starts when the $\mathrm{i}_{\text {lim }}$ is approached. The current is set under diffusion control and a plateau is formed in the current-voltage curves.

(iii) The so-called overlimiting region $\left(i>i_{\text {lim }}\right.$ ), where the ionic transport through the membrane is again enhanced. The generation of additional ionic species (water splitting), or the supply of ions from the bulk solution induced by the convective distortion of the diffusion boundary layer (gravitational convection and electroconvection) can increase the ionic transfer through the membrane beyond the $i_{\text {lim }}$ value [33].

The current-voltage characteristics are summarized in Table 4 for the different membrane/electrolyte systems studied. HDX 100 has higher electrical resistance than the Nafion 117 membrane for all the electrolytes considered. This general trend is usually reported in the literature [12,34], and the more tortuous counter-ion pathway of heterogeneous membranes has been pointed out as the reason for this difference [32,35]. The structure of heterogeneous membranes includes areas which are rich in inert binder, thus complicating the connection between the conducting channels available for the ion transport, as indicated schematically in Fig. 7(b) $[22,36]$. It must be also noted, that the higher thickness of the heterogeneous HDX 100 membrane may also contribute to the higher resistance of these membranes.

The different variation in electrical resistance obtained when changing from Nafion to HDX membranes for both electrolytes is yet another remarkable fact. While the electrical resistances of Nafion immersed in $\mathrm{Na}_{2} \mathrm{SO}_{4}$ solutions are approximately $75 \%$ of those of HDX, the resistances of Nafion obtained with $\mathrm{Fe}_{2}\left(\mathrm{SO}_{4}\right)_{3}$ solutions are only about $10 \%$ of the resistances of HDX. This difference between both membrane/electrolyte systems gives a hint about the important role of the size and 
charge of the ions on the ionic conductance of the membranes. As commented above, the chronopotentiometric responses of both membranes already indicated that the HDX 100 membrane has a pore size distribution broader than Nafion. In addition, this difference in electrical resistance observed for $\mathrm{Fe}(\mathrm{III})$ solutions reveals that a high proportion of the HDX 100 pores is smaller than the $\mathrm{Fe}^{3+}$ ions. The pores of larger size than $\mathrm{Fe}^{3+}$ contribute to conduct the current, whereas the pores of smaller size than $\mathrm{Fe}^{3+}$ ions are blocked and transformed into non-conducting regions, as depicted in Fig. 7(c). A similar hypothesis was used to estimate the pore size of various ion-exchange membranes in amine solutions of varying chain length by means of chronopotentiometry [22]. Furthermore, the stronger affinity of the fixed ion-exchange sites of the HDX membrane toward the multicharged $\mathrm{Fe}^{3+}$ ions could also imply a slower diffusion of these ions through the membrane structure.

In regard to the shape of the current-voltage curves obtained for $0.02 \mathrm{M} \mathrm{Fe}_{2}\left(\mathrm{SO}_{4}\right)_{3}$ (Fig. 8(b)), some singular characteristics make them different from those obtained for more diluted solutions. First, the ohmic region of both membranes exhibits a change of slope, which coincides with the current densities for which $U_{m}$ decreased in the chronopotentiograms. Accordingly, two different electrical resistances have been calculated: $\mathrm{R}_{1}$ for the lower current densities and $\mathrm{R}_{2}$ for higher current densities. As stated previously, the shift from the initial equilibrium state which gives rise to the dissociation of $\mathrm{FeSO}_{4}{ }^{+}$ions into the more conductive $\mathrm{Fe}^{3+}$ and $\mathrm{SO}_{4}{ }^{2-}$ ions causes the reduction of the electrical resistance of the membranes with increasing the current density. On the other hand, for more diluted solutions of $\mathrm{Fe}(\mathrm{III}), \mathrm{Fe}^{3+}$ ions are available at the initial equilibrium conditions, thus leading to a constant membrane resistance within the ohmic region. The extended plateau and the absence of overlimiting region is another singular characteristic of the curves of Fig. 8(b). The extended plateau is related to the formation of precipitates at the membrane surface. This phenomenon occurred only for concentrations of $\mathrm{Fe}_{2}\left(\mathrm{SO}_{4}\right)_{3}$ of $0.02 \mathrm{M}$ and implied a notorious increase in the resistance of the membrane system, as already observed from the chronopotentiograms of Fig. 5(c) and (d). Therefore, the layer of precipitates formed at the depleting side of the membranes originates the extended plateaus in the current-voltage curves. Moreover, the absence of the overlimiting region seems to be caused by the blockage of the membrane pores by the precipitates of iron. 
Apart from the different electrical resistances, the values of $i_{\text {lim }}$ are also different for both membrane systems. The $\mathrm{i}_{\text {lim }}$ values calculated for the heterogeneous HDX 100 membrane are in general lower than the $i_{\text {lims }}$ of the Nafion 117 membrane. The observation of decreased $i_{\text {lim }}$ values in heterogeneous membranes is commonly reported in the literature, and is attributed to the presence of areas of different conductance on the surface of ion-exchange membranes $[14,37,38]$. This phenomenon is explained by the fact that the current lines are deviated from a straight trajectory when they approach regions impermeable to ions, such as those corresponding to the reinforcing fabric or those rich in polymer binder. Consequently, there is a confluence of the current lines through the conducting pathways of the membrane matrix and the local current density in these regions is significantly higher than the average current density calculated for the whole membrane area [14]. This phenomenon is schematically illustrated in Fig. 7(d). The higher local current density of the ion conducting areas of the membrane implies an anticipated depletion of ions near these regions, which promotes the transition to the plateau at lower average current densities than the $\mathrm{i}_{\text {lim }}$ corresponding to a homogeneous membrane.

3.3.2 Behavior of homogeneous and heterogeneous membranes with multicomponent systems

The chronopotentiometric response obtained for both membranes with mixtures of $\mathrm{Na}_{2} \mathrm{SO}_{4}$ and $\mathrm{Fe}_{2}\left(\mathrm{SO}_{4}\right)_{3}$ are presented in Fig. 9. Nafion 117 shows a very different response from that obtained with $0.02 \mathrm{M} \mathrm{Fe} 2\left(\mathrm{SO}_{4}\right)_{3}$ at both low and high current densities. At low current densities, the chronopotentiograms of Nafion 117 already exhibit an inflexion point, which is different from the maximum in $U_{m}$ observed in the curves of Fig. 5(a). Then, in the range of current densities going approximately from 5 to $14 \mathrm{~mA} \cdot \mathrm{cm}^{-2}$ the decrease in $\mathrm{U}_{\mathrm{m}}$ associated with the dissociation of $\mathrm{FeSO}_{4}{ }^{+}$ions is also observed. In the case of HDX 100, the inflexion point observed with Nafion is absent and the shape of the chronopotentiograms is identical to that of Fig. 5(b). Apparently, the presence of $\mathrm{Na}^{+}$ions in the mixture does not alter the behavior of this membrane in the ohmic range of currents. 
At higher current densities, the response of Nafion 117 becomes very similar to that of the HDX 100 membrane. Instead of presenting two distinguished inflexion points as occurred in Fig. 5(c) for the highest current density, $U_{m}$ shows an increase from the first instants of the current pulse, and then this increase is attenuated with time. Moreover, when the current is stopped, the relaxation profile of the membrane voltage drop is also prolonged, in analogy with the results presented in Fig. 5(c) and (d). However, the shape of the plateau is less pronounced than that observed with $0.02 \mathrm{M} \mathrm{Fe}_{2}\left(\mathrm{SO}_{4}\right)_{3}$. These results suggest that the formation of precipitates is also taking place with the mixtures of sodium and iron, which was also verified at the end of the experiments. However, in this case the participation of $\mathrm{Na}^{+}$ions in the restoration of the concentration profiles near the membrane surface seems to contribute to the faster relaxation of the membrane potential.

As can be seen in Table 2, the main difference between the ionic species present in mixtures of $\mathrm{Na}_{2}\left(\mathrm{SO}_{4}\right)_{3}$ and $\mathrm{Fe}_{2}\left(\mathrm{SO}_{4}\right)_{3}$ and solutions of $0.02 \mathrm{M} \mathrm{Fe}{ }_{2}\left(\mathrm{SO}_{4}\right)_{3}$ is the presence of $\mathrm{Na}^{+}$ions in the electrolyte. Therefore, analyzing the current-voltage characteristics can be particularly useful in order to elucidate how the mixed transport of various metal ions takes place in systems of homogeneous and heterogeneous membranes. Fig. 10 shows the current-voltage curves obtained for Nafion and HDX with the multi-ionic mixtures.

The current-voltage curves obtained for the HDX 100 membrane are analogous to that obtained with $0.02 \mathrm{M} \mathrm{Fe}_{2}\left(\mathrm{SO}_{4}\right)_{3}$. The curves exhibit a quasi-ohmic region with a change in the electrical resistance, and the extended plateau associated with the formation of precipitates. Therefore, the presence of $\mathrm{Na}^{+}$ions in the electrolyte does not affect the formation of the reaction layer where the dissociation of $\mathrm{FeSO}_{4}{ }^{+}$ions occurs, and the change in membrane conductance is also promoted by the transport of $\mathrm{Fe}^{3+}$ through the membranes. In the mixture solutions, however, the $\mathrm{Na}^{+}$ions may be also transported through the membrane within the underlimiting range of currents.

On the contrary, the curves obtained for the Nafion membrane with multicomponent solutions differ significantly from those obtained in single salt solutions. The curves exhibit four different regions. First, the quasi-ohmic section appears in the range of low current densities, and then is followed by a plateau region, which coincides with the 
current densities at which the first inflexion points in $U_{m}$ are observed in the chronopotentiograms $\left(i=4.11 \mathrm{~mA} / \mathrm{cm}^{2}\right.$ in Figure 9 (a)). This first $i_{\lim }\left(i_{\lim 1}\right)$ may be associated with the depletion of $\mathrm{Na}^{+}$ions at the membrane surface, since the plateau is not observed with single salt solutions of Fe(III). In order to prove this hypothesis the effect of varying the concentration of $\mathrm{Na}^{+}$ions on the shape of the current-voltage curve was analyzed (as shown in Fig. 10), and the correspondence between the first plateau and the depletion of $\mathrm{Na}^{+}$ions was confirmed by an increase in the $\mathrm{i}_{\lim 1}$ values that was proportional to the increase in the concentration of $\mathrm{Na}^{+}$ions. For current densities higher than $i_{\text {lim } 1}$, a third region where the current density increases again with $U_{m}$ follows the first plateau. As occurred with single salt solutions of $\mathrm{Fe}(\mathrm{III})$, the conversion of $\mathrm{FeSO}_{4}{ }^{+}$ions (coming from the bulk solution and reaching the reaction layer next to the membrane) into the more mobile $\mathrm{Fe}^{3+}$ and $\mathrm{SO}_{4}{ }^{2-}$ ions also induces an increased conductance of the membranes. Finally, as observed for the HDX 100 membrane, the second $i_{\lim }\left(i_{\lim 2}\right)$ is determined by the formation of precipitates at the anodic side of the membrane.

The current-voltage parameters calculated from the curves obtained with multicomponent electrolytes are presented in Table 5. In addition to the different shape of the curves of both membranes, the values of electrical resistance at low and high current densities (where $\mathrm{R}_{2}$ refers to the region following the first plateau for the Nafion 117 membrane) also reveal a different behavior depending on the membrane structure. The values of $R_{1}$ are lower than $R_{2}$ for the Nafion membrane. On the contrary, the values of $R_{1}$ calculated for the HDX membrane are higher than $R_{2}$. The behavior of the HDX 100 membrane is analogous to that observed with $0.02 \mathrm{M} \mathrm{Fe} 2\left(\mathrm{SO}_{4}\right)_{3}$, with a decrease in the electrical resistance taking place for increasing current densities. Therefore, this trend may confirm that $\mathrm{Na}^{+}$ions contribute to carry the current over the entire quasi-ohmic region. At low current densities the ionic current would be simultaneously carried by $\mathrm{FeSO}_{4}{ }^{+}$and $\mathrm{Na}^{+}$ions, whereas at higher current densities it would be associated with the transport of $\mathrm{Fe}^{3+}$ and $\mathrm{Na}^{+}$ions. On the contrary, when the $\mathrm{i}_{\text {lim } 1}$ is reached, the supply of $\mathrm{Na}^{+}$ions to the surface of Nafion is limited by diffusion and their contribution to the membrane conductance diminishes at current densities higher than $\mathrm{i}_{\lim 1} . \mathrm{Fe}^{3+}$ ions are in consequence the main charge carriers at higher current densities, hence justifying the high values of $R_{2}$ obtained for the Nafion membrane if compared to those of $\mathrm{R}_{1}$. The greater supply of $\mathrm{Fe}^{3+}$ ions to the membrane surface in 
comparison with the limited transport of $\mathrm{Na}^{+}$ions is schematically represented in Fig. 7(e). As commented above, the preference of Nafion for $\mathrm{Na}^{+}$ions at low current densities is confirmed by the almost proportional increase of $i_{\lim 1}$ with the increase in the concentration of $\mathrm{Na}^{+}$ions. On the other hand, the $\mathrm{i}_{\lim 2}$ is not affected very much by the presence of $\mathrm{Na}^{+}$ions because it is mainly determined by the concentration of $\mathrm{Fe}(\mathrm{III})$, which was maintained constant.

The fact that the depletion of $\mathrm{Na}^{+}$ions near the membrane surface occurs with Nafion but not with HDX is also in agreement with the results obtained from the ion uptake experiments. Although both membranes absorb preferentially multicharged ions, the preference for $\mathrm{Fe}^{3+}$ instead of $\mathrm{Na}^{+}$ions is more marked in the case of the HDX membrane. Therefore, the smaller size of $\mathrm{Na}^{+}$ions and the higher affinity of Nafion for $\mathrm{Na}^{+}$ions in comparison with the HDX membrane would induce the depletion of $\mathrm{Na}^{+}$ ions at low current densities. Once the supply of monovalent ions to the membrane surface is set under diffusion control, the transport of $\mathrm{Fe}^{3+}$ ions should occur preferentially at higher current densities. On the contrary, in the case of the HDX membrane the high affinity of the membrane for $\mathrm{Fe}^{3+}$ ions along with the heterogeneous structure of HDX promotes a mixed transport of $\mathrm{Fe}^{3+}$ and $\mathrm{Na}^{+}$ions through the membrane. The ability of Nafion 117 for the separation between ions of different valence depending on the applied current density could have practical implications for those processes in which the separation of different cations is desired. Moreover, the higher permselectivity of these membranes for monovalent ions at low current densities could be used as a strategy to achieve the separation between cations of different valence, which could be applied in combination with other approaches already used for this purpose [39-41].

Finally, the differences in the electrical resistances obtained for single salt solutions of $\mathrm{Fe}_{2}\left(\mathrm{SO}_{4}\right)_{3}$ (see Table 4) and mixtures of $\mathrm{Na}_{2} \mathrm{SO}_{4}$ and $\mathrm{Fe}_{2}\left(\mathrm{SO}_{4}\right)_{3}$ (see Table 5) are also remarkable. For a constant concentration of $0.02 \mathrm{M} \mathrm{Fe}_{2}\left(\mathrm{SO}_{4}\right)_{3}$ the addition of $\mathrm{Na}_{2} \mathrm{SO}_{4}$, instead of reducing the electrical resistance of the membrane system, leads to an increase in the $R_{1}$ values. For both membranes, a maximum in $R_{1}$ is obtained for the mixture of $0.02 \mathrm{M} \mathrm{Fe}_{2}\left(\mathrm{SO}_{4}\right)_{3}$ and $0.01 \mathrm{M} \mathrm{Na} 2 \mathrm{SO}_{4}$, but then $\mathrm{R}_{1}$ decreases again with a further increase in the concentration of $\mathrm{Na}_{2} \mathrm{SO}_{4}$. In order to explain these results, we have to consider all the contributions to the voltage drop measured between the 
reference electrodes. The $U_{m}$ value includes the voltage drop through the membrane phase and the voltage drop of the diffusion boundary layers. With regard to the first contribution, a decrease in the electrical resistance of ion-exchange membranes with the dilution of the electrolyte was also observed in previous studies conducted with weak electrolytes [27,28]. This behavior was attributed to an enrichment of the membrane phase in multivalent cations as the electrolyte became diluted, which has been reported to originate an increased membrane electrical conductivity [27]. In the present study, an increase in the concentration of $\mathrm{Na}_{2} \mathrm{SO}_{4}$ involves the addition of more $\mathrm{SO}_{4}{ }^{2-}$ ions, which displace the equilibrium toward the formation of $\mathrm{FeSO}_{4}{ }^{+}$and $\mathrm{Fe}\left(\mathrm{SO}_{4}\right)_{2}^{-}$ions and decrease the concentration of free $\mathrm{Fe}^{3+}$ ions (as can be seen from the concentration of species obtained for $0.02 \mathrm{M} \mathrm{Fe}_{2}\left(\mathrm{SO}_{4}\right)_{3}$ solutions and varying concentrations of $\mathrm{Na}_{2} \mathrm{SO}_{4}$ shown in Table 2). Moreover, as already seen from the ion uptake equilibrium results (Fig. 3), the number of fixed charges of the membrane equilibrated with $\mathrm{Fe}$ (III) decreases as the concentration of $\mathrm{Na}_{2} \mathrm{SO}_{4}$ is increased. Therefore, this seems to be the reason for the increased values of $\mathrm{R}_{1}$ observed for the mixtures of $0.02 \mathrm{M} \mathrm{Fe}{ }_{2}\left(\mathrm{SO}_{4}\right)_{3}$ and $0.01 \mathrm{M} \mathrm{Na}_{2} \mathrm{SO}_{4}$. Nevertheless, a further increase in the concentration of $\mathrm{Na}_{2} \mathrm{SO}_{4}$ reduces again the $\mathrm{R}_{1}$ values. This behavior could be explained by the more important increase in the conductivity of the diffusion boundary layers, which in this case compensates the decrease in the amount multivalent ions bound to the membrane fixed charges. 


\section{Conclusions}

The metal ion transport through homogeneous perfluorosulfonic (Nafion 117) and heterogeneous (HDX 100) cation-exchange membranes was investigated in electrolyte systems composed of $\mathrm{Na}_{2} \mathrm{SO}_{4}$ and $\mathrm{Fe}_{2}\left(\mathrm{SO}_{4}\right)_{3}$ single salt solutions, and in multicomponent mixtures of both salts. The main conclusions of our study are summarized as follows:

- The simultaneous depletion of ions occurring near homogeneous membranes confirms that all their pores have similar size and ion-exchange properties. On the contrary, the smoother chronopotentiometric response obtained for heterogeneous membranes indicates an irregular development of concentration polarization at the surface of these membranes, which is a proof of a broader distribution of pore sizes and ion-exchange sites.

- The transport of concentrated solutions of Fe(III) showed an atypical behavior for both the homogeneous and heterogeneous membranes, since the membrane resistances decreased once a certain current density was exceeded. This phenomenon was explained to be a consequence of the dissociation of $\mathrm{FeSO}_{4}{ }^{+}$ ions into more conductive $\mathrm{Fe}^{3+}$ and $\mathrm{SO}_{4}{ }^{2-}$ ions, which is promoted by the dilution of the diffusion boundary layer.

- The selectivity of the membranes with mixtures of $\mathrm{Na}(\mathrm{I})$ and $\mathrm{Fe}(\mathrm{III})$ is markedly different. The heterogeneous structure of the HDX 100 membrane and its strong affinity for trivalent iron lead to a mixed transport of $\mathrm{Na}^{+}$and $\mathrm{Fe}(\mathrm{III})$ species within the underlimiting range of currents. On the contrary Nafion shows a higher preference for $\mathrm{Na}^{+}$ions at low current densities. The current-voltage curves of Nafion show a plateau at $\mathrm{i} \approx \mathrm{i}_{\lim 1}$ associated with the depletion of $\mathrm{Na}^{+}$ ions. On the contrary, at currents higher than $\mathrm{i}_{\text {lim1 }}$ when the $\mathrm{Na}^{+}$ions have already been depleted from the membrane surface, the ion transport through the Nafion membrane is mainly associated with the transport of $\mathrm{Fe}^{3+}$ ions.

- The electrical resistance of the different membrane/electrolyte systems has a strong dependence on the type of ions that are balancing the membrane fixed charges. We have observed a decrease in the $R_{1}$ values when the equilibrium relations favor a higher fraction of multicharged ions in the membrane phase, 
even in some cases where this change in the equilibrium composition was a result of the dilution of the external equilibrating solution. 


\section{Acknowledgements}

This work was supported by the Ministerio de Economía y Competitividad (Spain) with the project number CTQ2012-27450-C02-01/PPQ. M.C. Martí-Calatayud is grateful to the Universitat Politècnica de València for a postgraduate grant (Ref. 2010-12). D.C. Buzzi wants to express her gratitude to CAPES (Brazil) for a postgraduate grant (Proc. BEX 8747/11-3). 


\section{Appendix}

The speciation of the different solutions used in the present study was obtained from the different equilibriums of formation of complex species. The formation of complex species of $\mathrm{Fe}^{3+}$ with $\mathrm{OH}^{-}$ions is described by Eqs. (2)-(5) [42]:

$$
\begin{array}{lc}
\mathrm{Fe}^{3+}+\mathrm{OH}^{-} \rightleftarrows \mathrm{FeOH}^{2+} & \beta_{1}=10^{11.81} \\
\mathrm{Fe}^{3+}+2 \mathrm{OH}^{-} \rightleftarrows \mathrm{Fe}(\mathrm{OH})_{2}{ }^{+} & \beta_{2}=10^{22.3} \\
\mathrm{Fe}^{3+}+3 \mathrm{OH}^{-} \rightleftarrows \mathrm{Fe}(\mathrm{OH})_{3} & \beta_{3}=10^{30} \\
\mathrm{Fe}^{3+}+4 \mathrm{OH}^{-} \rightleftarrows \mathrm{Fe}(\mathrm{OH})_{4}^{-} & \beta_{4}=10^{34.4}
\end{array}
$$

The complexation of $\mathrm{Fe}^{3+}$ with $\mathrm{SO}_{4}{ }^{2-}$ ions as ligands was also taken into account with the Eqs. (6) and (7):

$$
\begin{array}{ll}
\mathrm{Fe}^{3+}+\mathrm{SO}_{4}{ }^{2-} \rightleftarrows \mathrm{FeSO}_{4}{ }^{+} & \beta_{1}^{\prime}=10^{4.04} \\
\mathrm{Fe}^{3+}+2 \mathrm{SO}_{4}{ }^{2-} \rightleftarrows \mathrm{Fe}\left(\mathrm{SO}_{4}\right)_{2}{ }^{-} & \beta_{2}^{\prime}=10^{5.38}
\end{array}
$$

Moreover, the formation of precipitates was also considered:

$$
\mathrm{Fe}^{3+}+3 \mathrm{OH}^{-} \rightleftarrows \mathrm{Fe}(\mathrm{OH})_{3}(\mathrm{~s}) \quad \mathrm{K}_{\mathrm{s}}\left(\mathrm{Fe}(\mathrm{OH})_{3}\right)=10^{-38.8}
$$

In the case of $\mathrm{Na}^{+}$ions, the following equilibria were considered:

$$
\begin{array}{ll}
\mathrm{Na}^{+}+\mathrm{OH}^{-} \rightleftarrows \mathrm{NaOH} & \beta_{1}=10^{-0.2} \\
\mathrm{Na}^{+}+\mathrm{SO}_{4}{ }^{2-} \rightleftarrows \mathrm{NaSO}_{4}^{-} & \beta^{\prime}=10^{0.7}
\end{array}
$$

Besides, $\mathrm{SO}_{4}{ }^{2-}$ ions can also participate in hydrolysis reactions, which are given by Eq. (11) and (12):

$$
\begin{array}{lc}
\mathrm{H}_{2} \mathrm{SO}_{4} \rightleftarrows \mathrm{HSO}_{4}{ }^{-}+\mathrm{H}^{+} & \mathrm{K}_{\mathrm{H} 1}=10^{3} \\
\mathrm{HSO}_{4}{ }^{-} \rightleftarrows \mathrm{SO}_{4}{ }^{2-}+\mathrm{H}^{+} & \mathrm{K}_{\mathrm{H} 2}=10^{-1.99}
\end{array}
$$

The stability constants of the reactions presented above are defined as follows: 
$\beta_{i}=\frac{\left[M(O H)_{i}^{n-i}\right]}{\left[M^{+n}\right] \times\left[\mathrm{OH}^{-}\right]^{i}}$

$\beta_{i}^{\prime}=\frac{\left[M\left(\mathrm{SO}_{4}\right)_{i}^{n-2 i}\right]}{\left[\mathrm{M}^{+n}\right] \times\left[\mathrm{SO}_{4}^{2-}\right]^{i}}$

$K_{S}=\left[M^{+n}\right] \times\left[O H^{-}\right]^{n}$

$K_{H i}=\frac{\left[H^{+}\right] \times\left[H_{2-i} S_{4}^{-i}\right]}{\left[H_{3-i} S_{4}^{1-i}\right]}$

In order to calculate the concentrations of each species, the system of equations formed by the mass balance of sulfates, $\mathrm{Fe}(\mathrm{III})$ species and $\mathrm{Na}(\mathrm{I})$ species (Eqs. (17)-(19)) together with the proton balance given by Eq. (20) was solved:

$[\mathrm{Fe}(\mathrm{III})]_{0}=\left[\mathrm{Fe}^{3+}\right]+\left[\mathrm{FeOH}^{2+}\right]+\left[\mathrm{Fe}(\mathrm{OH})_{2}{ }^{+}\right]+\left[\mathrm{Fe}(\mathrm{OH})_{3}\right]+\left[\mathrm{Fe}(\mathrm{OH})_{4}{ }^{-}\right]+\left[\mathrm{FeSO}_{4}{ }^{+}\right]+$ $\left[\mathrm{Fe}\left(\mathrm{SO}_{4}\right)_{2}{ }^{-}\right]$

$[\mathrm{Na}(\mathrm{I})]_{0}=\left[\mathrm{Na}^{+}\right]+[\mathrm{NaOH}]+\left[\mathrm{NaSO}_{4}^{-}\right]$

$\left[\mathrm{SO}_{4}{ }^{2-}\right]_{0}=\left[\mathrm{SO}_{4}{ }^{2-}\right]+\left[\mathrm{FeSO}_{4}{ }^{+}\right]+2\left[\mathrm{Fe}\left(\mathrm{SO}_{4}\right)_{2}^{-}\right]+\left[\mathrm{HSO}_{4}{ }^{-}\right]+\left[\mathrm{H}_{2} \mathrm{SO}_{4}\right]+\left[\mathrm{NaSO}_{4}{ }^{-}\right]$

$\left[\mathrm{H}^{+}\right]=\left[\mathrm{OH}^{-}\right]+\left[\mathrm{FeOH}^{2+}\right]+2\left[\mathrm{Fe}(\mathrm{OH})_{2}{ }^{+}\right]+3\left[\mathrm{Fe}(\mathrm{OH})_{3}\right]+4\left[\mathrm{Fe}(\mathrm{OH})_{4}{ }^{-}\right]+[\mathrm{NaOH}]$ $\left[\mathrm{HSO}_{4}^{-}\right]-2\left[\mathrm{H}_{2} \mathrm{SO}_{4}\right]$ 


\section{References}

[1] S.H. Moon, S.H. Yun, Process integration of electrodialysis for a cleaner environment, Curr. Opin. Chem. Eng., 4 (2014) 25-31.

[2] M.Y. Kariduraganavar, R.K. Nagarale, A.A. Kittur, S.S. Kulkarni, Ion-exchange membranes: preparative methods for electrodialysis and fuel cell applications, Desalination, 197 (2006) 225-246.

[3] Treatment of Acid Mine Drainage. House of Commons Library, London, 1999.

[4] D.C. Buzzi, L.S. Viegas, M.A.S. Rodrigues, A.M. Bernardes, J.A.S. Tenório, Water recovery from acid mine drainage by electrodialysis, Miner. Eng., 40 (2013) 82-89.

[5] M.C. Martí-Calatayud, D.C. Buzzi, M. García-Gabaldón, E. Ortega, A.M. Bernardes, J.A.S. Tenório, V. Pérez-Herranz, Sulfuric acid recovery from acid mine drainage by means of electrodialysis, Desalination (2013), http://dx.doi.org/10.1016/j.desal.2013.11.031

[6] M.C. Martí-Calatayud, M. García-Gabaldón, V. Pérez-Herranz, S. Sales, S. Mestre, Synthesis and electrochemical behavior of ceramic cation-exchange membranes based on zirconium phosphate, Ceram. Int., 39 (2013) 4045-4054.

[7] P.V. Vyas, B.G. Shah, G.S. Trivedi, P. Ray, S.K. Adhikary, R. Rangarajan, Characterization of heterogeneous anion-exchange membrane, J. Membr. Sci., 187 (2001) 39-46.

[8] P.V. Vyas, B.G. Shah, G.S. Trivedi, P. Ray, S.K. Adhikary, R. Rangarajan, Studies on heterogeneous cation-exchange membranes, React. Funct. Polym., 44 (2000) 101-110.

[9] V.I. Zabolotsky, V.V. Nikonenko, Effect of structural membrane inhomogeneity on transport properties, J. Membr. Sci., 79 (1993) 181-198.

[10] X.T. Le, T.H. Bui, P. Viel, T. Berthelot, S. Palacin, On the structure-properties relationship of the AMV anion exchange membrane, J. Membr. Sci., 340 (2009) 133-140.

[11] Y. Mizutani, Structure of ion exchange membranes, J. Membr. Sci., 49 (1990) 121-144.

[12] J.H. Choi, S.H. Kim, S.H. Moon, Heterogeneity of ion-exchange membranes: the effects of membrane heterogeneity on transport properties, J. Colloid Interface Sci., 241 (2001) 120-126.

[13] J. Balster, M.H. Yildirim, D.F. Stamatialis, R. Ibanez, R.G.H. Lammertink, V. Jordan, M. Wessling, Morphology and microtopology of cation-exchange polymers and the origin of the overlimiting current, J. Phys. Chem. B, 111 (2007) 2152-2165. 
[14] E. Volodina, N. Pismenskaya, V. Nikonenko, C. Larchet, G. Pourcelly, Ion transfer across ion-exchange membranes with homogeneous and heterogeneous surfaces, J. Colloid Interface Sci., 285 (2005) 247-258.

[15] W.Y. Hsu, T.D. Gierke, Ion transport and clustering in Nafion perfluorinated membranes, J. Membr. Sci., 13 (1983) 307-326.

[16] K.A. Mauritz, R.B. Moore, State of understanding of Nafion, Chem. Rev., 104 (2004) 4535-4585.

[17] K. Schmidt-Rohr, Q. Chen, Parallel cylindrical water nanochannels in Nafion fuelcell membranes, Nat. Mater., 7 (2008) 75-83.

[18] A. Chapotot, G. Pourcelly, C. Gavach, Transport competition between monovalent and divalent cations through cation-exchange membranes. Exchange isotherms and kinetic concepts, J. Membr. Sci., 96 (1994) 167-181.

[19] S. Logette, C. Eysseric, G. Pourcelly, A. Lindheimer, C. Gavach, Selective permeability of a perfluorosulphonic membrane to different valency cations. Ionexchange isotherms and kinetic aspects, J. Membr. Sci., 144 (1998) 259-274.

[20] F. Maletzki, H.W. Rösler, E. Staude, Ion transfer across electrodialysis membranes in the overlimiting current range: stationary voltage current characteristics and current noise power spectra under different conditions of free convection, J. Membr. Sci., 71 (1992) 105-116.

[21] E.I. Belova, G.Y. Lopatkova, N.D. Pismenskaya, V.V. Nikonenko, C. Larchet, G. Pourcelly, Effect of anion-exchange membrane surface properties on mechanisms of overlimiting mass transfer, J. Phys. Chem. B, 110 (2006) 13458-13469.

[22] J.H. Choi, S.H. Moon, Pore size characterization of cation-exchange membranes by chronopotentiometry using homologous amine ions, J. Membr. Sci., 191 (2001) 225-236.

[23] F.G. Wilhelm, N.F.A. van der Vegt, M. Wessling, H. Strathmann, Chronopotentiometry for the advanced current-voltage characterisation of bipolar membranes, J. Electroanal. Chem., 502 (2001) 152-166.

[24] F.G. Wilhelm, N.F.A. van der Vegt, H. Strathmann, M. Wessling, Comparison of bipolar membranes by means of chronopotentiometry, J. Membr. Sci., 199 (2002) 177-190.

[25] M.C. Martí-Calatayud, M. García-Gabaldón, V. Pérez-Herranz, Effect of the equilibria of multivalent metal sulfates on the transport through cation-exchange membranes at different current regimes, J. Membr. Sci., 443 (2013) 181-192.

[26] M. García-Gabaldón, V. Pérez-Herranz, E. Ortega, Evaluation of two ionexchange membranes for the transport of tin in the presence of hydrochloric acid, J. Membr. Sci., 371 (2011) 65-74. 
[27] N.D. Pismenskaya, E.I. Belova, V.V. Nikonenko, C. Larchet, Electrical conductivity of cation- and anion-exchange membranes in ampholyte solutions, Russ. J. Electrochem., 44 (2008) 1285-1291.

[28] N. Pismenskaya, E. Laktionov, V. Nikonenko, A. El Attar, B. Auclair, G. Pourcelly, Dependence of composition of anion-exchange membranes and their electrical conductivity on concentration of sodium salts of carbonic and phosphoric acids, J. Membr. Sci., 181 (2001) 185-197.

[29] V. Nikonenko, K. Lebedev, J.A. Manzanares, G. Pourcelly, Modelling the transport of carbonic acid anions through anion-exchange membranes, Electrochim. Acta, 48 (2003) 3639-3650.

[30] D.R. Lide, CRC Handbook of Chemistry and Physics, $70^{\text {th }}$ ed., CRC Press Inc., Boca Raton, 2009.

[31] J.M. Casas, G. Crisóstomo, L. Cifuentes, Speciation of the $\mathrm{Fe}(\mathrm{II})-\mathrm{Fe}(\mathrm{III})-\mathrm{H}_{2} \mathrm{SO}_{4}$ $\mathrm{H}_{2} \mathrm{O}$ system at 25 and $50^{\circ} \mathrm{C}$, Hydrometallurgy, 80 (2005) 254-264.

[32] H. Strathmann, Electrodialysis, a mature technology with a multitude of new applications, Desalination, 264 (2010) 268-288.

[33] M.C. Martí-Calatayud, M. García-Gabaldón, V. Pérez-Herranz, E. Ortega, Determination of transport properties of Ni(II) through a Nafion cation-exchange membrane in chromic acid solutions, J. Membr. Sci., 379 (2011) 449-458.

[34] V.M. Barragán, J.P.G. Villaluenga, M.P. Godino, M.A. Izquierdo-Gil, C. RuizBauzá, B. Seoane, Experimental estimation of equilibrium and transport properties of sulfonated cation-exchange membranes with different morphologies, J. Colloid Interface Sci., 333 (2009) 497-502.

[35] W. Garcia-Vasquez, R. Ghalloussi, L. Dammak, C. Larchet, V. Nikonenko, D. Grande, Structure and properties of heterogeneous and homogeneous ionexchange membranes subjected to ageing in sodium hypochlorite, J. Membr. Sci., 452 (2014) 104-116.

[36] R.K. Nagarale, V.K. Shahi, S.K. Thampy, R. Rangarajan, Studies on electrochemical characterization of polycarbonate and polysulfone based heterogeneous cation-exchange membranes, React. Funct. Polym., 61 (2004) 131138.

[37] E.D. Belashova, N.A. Melnik, N.D. Pismenskaya, K.A. Shevtsova, A.V. Nebavsky, K.A. Lebedev, V.V. Nikonenko, Overlimiting mass transfer through cation-exchange membranes modified by Nafion film and carbon nanotubes, Electrochim. Acta, 59 (2012) 412-423.

[38] N.D. Pismenskaya, V.V. Nikonenko, N.A. Melnik, K.A. Shevtsova, E.I. Belova, G. Pourcelly, D. Cot, L. Dammak, C. Larchet, Evolution with time of hydrophobicity and microrelief of a cation-exchange membrane surface and its impact on overlimiting mass transfer, J. Phys. Chem. B, 116 (2011) 2145-2161. 
[39] S. Abdu, M.C. Martí-Calatayud, J.E. Wong, M. García-Gabaldón, M. Wessling, Layer-by-Layer modification of cation exchange membranes controls ion selectivity and water splitting, ACS Appl. Mater. Interfaces, 6 (2014) 1843-1854.

[40] M. Wang, Y. Jia, T. Yao, K. Wang, The endowment of monovalent selectivity to cation exchange membrane by photo-induced covalent immobilization and selfcrosslinking of chitosan, J. Membr. Sci., 442 (2013) 39-47.

[41] T. Chakrabarty, B. Shah, N. Srivastava, V. K. Shahi, U. Chudasama, Zirconium tri-ethylene tetra-amine ligand-chelator complex based cross-linked membrane for selective recovery of $\mathrm{Cu}^{2+}$ by electrodialysis, J. Membr. Sci., 428 (2013) 462-469.

[42] S. Kotrlý, L. Sucha, Handbook of Chemical Equilibria in Analytical Chemistry, Ellis Horwood Ltd., Chinchester, 1985. 


\section{LIST OF TABLES.}

Table 1. Chemical characterization of AMD samples. The concentration of species is given in $\mathrm{mol} \cdot \mathrm{L}^{-1}$.

Table 2. Ionic species present in the solutions used to conduct the experiments

Table 3. Ionic conductivity $\left(\lambda_{\mathrm{i}}\right)$ and diffusion coefficients $\left(\mathrm{D}_{\mathrm{i}}\right)$ of various ionic species present in the solutions (Taken from [30,31]).

Table 4. Current-voltage characteristics obtained for the Nafion 117 and the HDX 100 membranes with single salt solutions.

Table 5. Current-voltage characteristics in multicomponent systems. 


\section{LIST OF FIGURES.}

Fig. 1. Experimental setup used for the chronopotentiometric experiments.

Figure 2. SEM micrographs of different membranes: (a) surface and (b) cross section of Nafion 117 obtained at $60 \mu \mathrm{m}$, (c) surface and (d) cross section of HDX 100 obtained at $600 \mu \mathrm{m}$ and, (e) surface and (f) cross section of HDX 100 obtained at $60 \mu \mathrm{m}$.

Fig. 3. (a) Concentration of iron and sodium equilibrated in the membrane phase as a function of the electrolyte composition and (b) variation of the $[\mathrm{Na}(\mathrm{I})] /[\mathrm{Fe}(\mathrm{III})]$ ratio in the membrane phase with the $[\mathrm{Na}(\mathrm{I})] /[\mathrm{Fe}(\mathrm{III})]$ ratio in the electrolyte solution for the Nafion 117 and HDX 100 membrane.

Fig. 4. Chronopotentiometric response obtained with $0.01 \mathrm{M} \mathrm{Na}_{2} \mathrm{SO}_{4}$ solutions with (a) Nafion 117 and (b) HDX 100 membrane.

Fig. 5. Chronopotentiometric response obtained with $0.02 \mathrm{M} \mathrm{Fe}_{2}\left(\mathrm{SO}_{4}\right)_{3}$ solutions in the underlimiting range of currents for (a) Nafion 117 and (b) HDX 100; and in the overlimiting range of currents for (c) Nafion 117 and (d) HDX 100.

Fig. 6. Chronopotentiometric response obtained with $0.001 \mathrm{M} \mathrm{Fe}_{2}\left(\mathrm{SO}_{4}\right)_{3}$ solutions with (a) Nafion 117 and (b) HDX 100 membrane.

Fig. 7. Schematic representation of several transport processes taking place through the ion-exchange membranes. (a) Dissociation of $\mathrm{FeSO}_{4}{ }^{+}$ions at the anodic boundary layer of the membranes occurring when a certain polarization level is reached, (b) comparison between the counter-ion pathway through homogeneous and heterogeneous membranes (adapted from [29]), (c) blocking of membrane pores of smaller size than the electrolyte counter-ions (adapted from [19]), (d) distribution of current lines near the surface of homogeneous and heterogeneous membranes (adapted from [14]), and (e) concentration profiles of $\mathrm{Fe}^{3+}$ and $\mathrm{Na}^{+}$ions near the anodic side of the Nafion membrane under the application of currents higher than $\mathrm{i}_{\lim 1}$.

Fig. 8. Current-voltage curves obtained with the homogeneous Nafion 117 and heterogeneous HDX 100 membrane (a) with systems of diluted single salt solutions of $\mathrm{Na}_{2} \mathrm{SO}_{4}$ and $\mathrm{Fe}_{2}\left(\mathrm{SO}_{4}\right)_{3}$ and (b) with systems of $0.02 \mathrm{M} \mathrm{Fe}_{2}\left(\mathrm{SO}_{4}\right)_{3}$ solutions.

Figure 9. Chronopotentiometric response obtained with multicomponent salt mixtures of $0.02 \mathrm{M} \mathrm{Fe}_{2}\left(\mathrm{SO}_{4}\right)_{3}$ and $0.01 \mathrm{M} \mathrm{Na}_{2} \mathrm{SO}_{4}$ obtained at low and intermediate values of current (a) for the Nafion 117 membrane and (b) for the HDX 100 membrane; and at high values of current (c) for the Nafion 117 membrane and (d) for the HDX 100 membrane. 
Fig. 10. Current-voltage curves obtained for the homogeneous Nafion 117 and heterogeneous HDX 100 membranes with multicomponent salt mixtures of $\mathrm{Fe}_{2}\left(\mathrm{SO}_{4}\right)_{3}$ and $\mathrm{Na}_{2} \mathrm{SO}_{4}$. 
Table 1. Chemical characterization of AMD samples. The concentration of species is given in $\mathrm{mol} \cdot \mathrm{L}^{-1}$.

\begin{tabular}{cccccccccc}
$\mathrm{pH}$ & {$\left[\mathrm{Na}^{+}\right]$} & {$\left[\mathrm{K}^{+}\right]$} & {$\left[\mathrm{Mg}^{2+}\right]$} & {$\left[\mathrm{Ca}^{2+}\right]$} & {$\left[\mathrm{Fe}^{3+}\right]$} & {$\left[\mathrm{Zn}^{2+}\right]$} & {$\left[\mathrm{Mn}^{2+}\right]$} & {$\left[\mathrm{Cl}^{-}\right]$} & {$\left[\mathrm{SO}_{4}^{2-}\right]$} \\
\hline 2.48 & 0.017 & 0.004 & 0.006 & 0.006 & 0.037 & 0 & 0.001 & 0.008 & 0.082
\end{tabular}


Table 2. Ionic species present in the solutions used to conduct the experiments

\begin{tabular}{|c|c|c|c|c|c|c|c|c|c|}
\hline & $\mathrm{Fe}^{3+}$ & $\mathrm{FeSO}_{4}^{+}$ & $\mathrm{Fe}\left(\mathrm{SO}_{4}\right)_{2}^{-}$ & $\mathrm{FeOH}^{2+}$ & $\mathrm{Fe}(\mathrm{OH})_{2}^{+}$ & $\mathrm{Na}^{+}$ & $\mathrm{NaSO}_{4}^{-}$ & $\mathrm{SO}_{4}{ }^{2-}$ & $\mathrm{HSO}_{4}^{-}$ \\
\hline $0.01 \mathrm{M} \mathrm{Na}_{2} \mathrm{SO}_{4}$ & - & - & - & - & - & $1.91 \cdot 10^{-2}$ & $8.76 \cdot 10^{-4}$ & $9.14 \cdot 10^{-3}$ & $1.82 \cdot 10^{-11}$ \\
\hline $0.001 \mathrm{M} \mathrm{Fe}_{2}\left(\mathrm{SO}_{4}\right)_{3}$ & $2.43 \cdot 10^{-4}$ & $1.61 \cdot 10^{-3}$ & $2.13 \cdot 10^{-5}$ & $1.24 \cdot 10^{-4}$ & $3.05 \cdot 10^{-6}$ & - & - & $6.05 \cdot 10^{-4}$ & $7.44 \cdot 10^{-4}$ \\
\hline $0.02 \mathrm{M} \mathrm{Fe}_{2}\left(\mathrm{SO}_{4}\right)_{3}$ & $4.84 \cdot 10^{-4}$ & $3.41 \cdot 10^{-2}$ & $5.19 \cdot 10^{-3}$ & $2.30 \cdot 10^{-4}$ & $5.64 \cdot 10^{-6}$ & - & - & $6.95 \cdot 10^{-3}$ & $8.55 \cdot 10^{-3}$ \\
\hline \multicolumn{10}{|l|}{$0.02 \mathrm{M} \mathrm{Fe}_{2}\left(\mathrm{SO}_{4}\right)_{3}$} \\
\hline+ & $2.95 \cdot 10^{-4}$ & $3.24 \cdot 10^{-2}$ & $7.11 \cdot 10^{-3}$ & $1.51 \cdot 10^{-4}$ & $3.72 \cdot 10^{-6}$ & $1.90 \cdot 10^{-2}$ & $9.56 \cdot 10^{-4}$ & $1.00 \cdot 10^{-2}$ & $1.23 \cdot 10^{-2}$ \\
\hline \multicolumn{10}{|l|}{$0.01 \mathrm{M} \mathrm{Na}_{2} \mathrm{SO}_{4}$} \\
\hline \multicolumn{10}{|l|}{$0.02 \mathrm{M} \mathrm{Fe}_{2}\left(\mathrm{SO}_{4}\right)_{3}$} \\
\hline+ & $2.16 \cdot 10^{-4}$ & $3.09 \cdot 10^{-2}$ & $8.81 \cdot 10^{-3}$ & $1.11 \cdot 10^{-4}$ & $2.72 \cdot 10^{-6}$ & $3.75 \cdot 10^{-2}$ & $2.46 \cdot 10^{-3}$ & $1.31 \cdot 10^{-2}$ & $1.61 \cdot 10^{-2}$ \\
\hline
\end{tabular}


Table 3. Ionic conductivity $\left(\lambda_{\mathrm{i}}\right)$ and diffusion coefficients $\left(\mathrm{D}_{\mathrm{i}}\right)$ of various ionic species present in the solutions (Taken from $[30,31]$ ).

\begin{tabular}{lcc} 
& $10^{-9} \mathrm{D}_{\mathrm{i}}\left(\mathrm{m}^{2} \cdot \mathrm{s}^{-1}\right)$ & $\lambda_{\mathrm{i}}\left(\mathrm{mS} \cdot \mathrm{m}^{2} \cdot \mathrm{mol}^{-1}\right)$ \\
\hline $\mathrm{Fe}^{3+}$ & 0.604 & 20.40 \\
$\mathrm{SO}_{4}{ }^{2-}$ & 1.065 & 16.00 \\
$\mathrm{FeSO}_{4}{ }^{+}$ & 0.201 & 0.76 \\
$\mathrm{Na}^{+}$ & 1.334 & 5.01
\end{tabular}


Table 4. Current-voltage characteristics obtained for the Nafion 117 and the HDX 100 membranes with single salt solutions.

\begin{tabular}{|c|c|c|c|c|c|c|c|c|}
\hline & \multicolumn{4}{|c|}{ Nafion 117} & \multicolumn{4}{|c|}{ HDX 100} \\
\hline & $0.01 \mathrm{M}$ & $0.02 \mathrm{M}$ & $0.001 \mathrm{M}$ & $0.02 \mathrm{M}$ & $0.01 \mathrm{M}$ & $0.02 \mathrm{M}$ & $0.001 \mathrm{M}$ & $0.02 \mathrm{M}$ \\
\hline & $\mathrm{Na}_{2} \mathrm{SO}_{4}$ & $\mathrm{Na}_{2} \mathrm{SO}_{4}$ & $\mathrm{Fe}_{2}\left(\mathrm{SO}_{4}\right)_{3}$ & $\mathrm{Fe}_{2}\left(\mathrm{SO}_{4}\right)_{3}$ & $\mathrm{Na}_{2} \mathrm{SO}_{4}$ & $\mathrm{Na}_{2} \mathrm{SO}_{4}$ & $\mathrm{Fe}_{2}\left(\mathrm{SO}_{4}\right)_{3}$ & $\mathrm{Fe}_{2}\left(\mathrm{SO}_{4}\right)_{3}$ \\
\hline $\begin{array}{c}\mathrm{R}_{1} \\
\left(\Omega \cdot \mathrm{cm}^{2}\right)\end{array}$ & 44.50 & 25.97 & 75.57 & 5.65 & 60.36 & 34.09 & 599.32 & 141.07 \\
\hline $\begin{array}{c}\mathrm{R}_{2} \\
\left(\Omega \cdot \mathrm{cm}^{2}\right)\end{array}$ & - & - & - & 3.61 & - & - & - & 39.01 \\
\hline $\begin{array}{c}\mathrm{i}_{\mathrm{lim}} \\
\left(\mathrm{mA} \cdot \mathrm{cm}^{-2}\right)\end{array}$ & 1.13 & 2.83 & 0.92 & 17.00 & 0.99 & 2.55 & 0.85 & 14.19 \\
\hline
\end{tabular}


Table 5. Current-voltage characteristics in multicomponent systems.

\begin{tabular}{cccccc} 
& \multicolumn{2}{c}{ Nafion 117} & & \multicolumn{2}{c}{$\mathrm{HDX} 100$} \\
\cline { 2 - 3 } \cline { 5 - 5 } & $0.01 \mathrm{M} \mathrm{Na}_{2} \mathrm{SO}_{4}$ & $0.02 \mathrm{M} \mathrm{Na}_{2} \mathrm{SO}_{4}$ & & $0.01 \mathrm{M} \mathrm{Na}_{2} \mathrm{SO}_{4}$ & $0.02 \mathrm{M} \mathrm{Na}_{2} \mathrm{SO}_{4}$ \\
& $0.02 \mathrm{M} \mathrm{Fe}_{2}\left(\mathrm{SO}_{4}\right)_{3}$ & $0.02 \mathrm{M} \mathrm{Fe}_{2}\left(\mathrm{SO}_{4}\right)_{3}$ & & $0.02 \mathrm{M} \mathrm{Fe}_{2}\left(\mathrm{SO}_{4}\right)_{3}$ & $0.02 \mathrm{M} \mathrm{Fe}_{2}\left(\mathrm{SO}_{4}\right)_{3}$ \\
$\mathrm{R}_{1}\left(\Omega \cdot \mathrm{cm}^{2}\right)$ & 22.60 & 9.16 & & 152.99 & 105.37 \\
$\mathrm{R}_{2}\left(\Omega \cdot \mathrm{cm}^{2}\right)$ & 136.42 & 61.47 & & 71.08 & 36.82 \\
$\mathrm{i}_{\lim 1}\left(\mathrm{~mA} \cdot \mathrm{cm}^{-2}\right)$ & 3.40 & 7.44 & & - & - \\
$\mathrm{i}_{\lim 2}\left(\mathrm{~mA} \cdot \mathrm{cm}^{-2}\right)$ & 13.61 & 15.15 & & 13.73 & 13.73
\end{tabular}




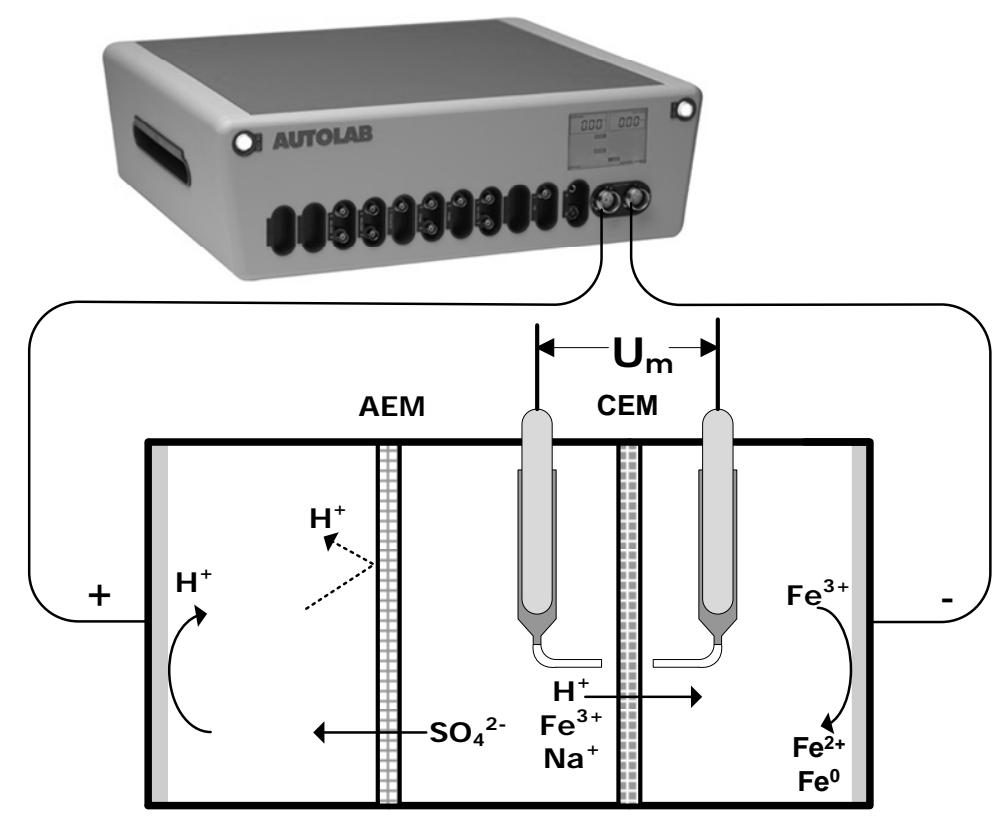

Fig. 1. Experimental setup used for the chronopotentiometric experiments. 
(a)

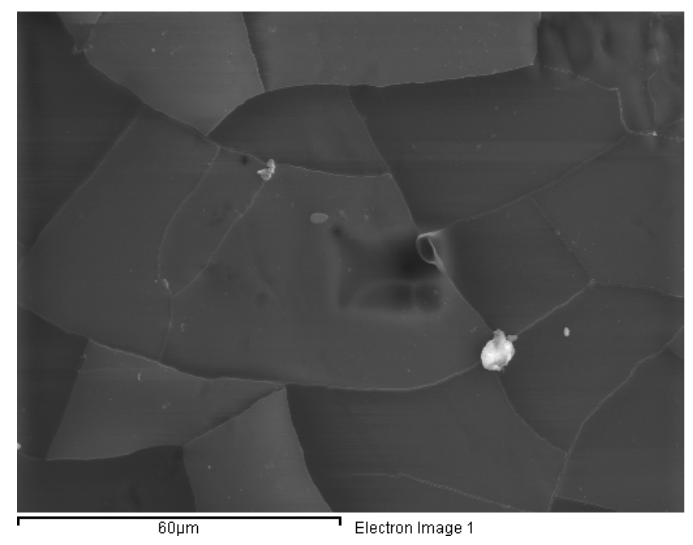

(c)

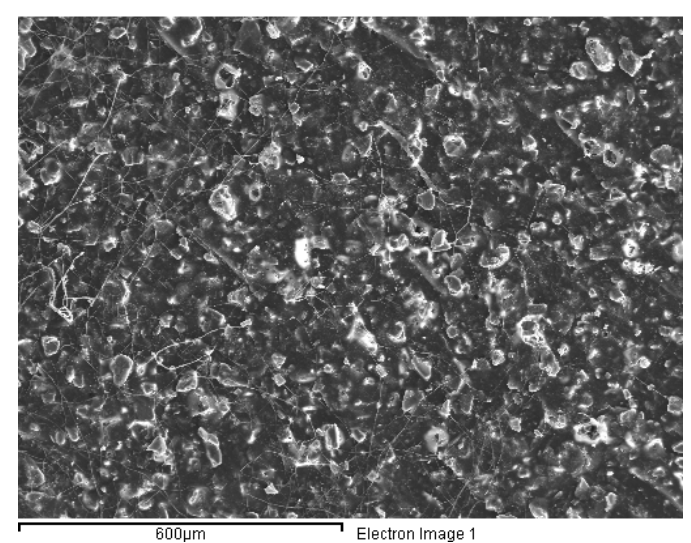

(e)

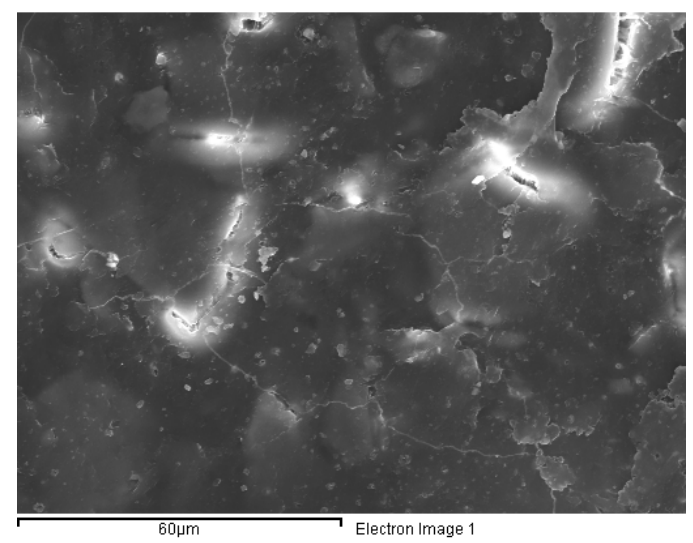

(b)

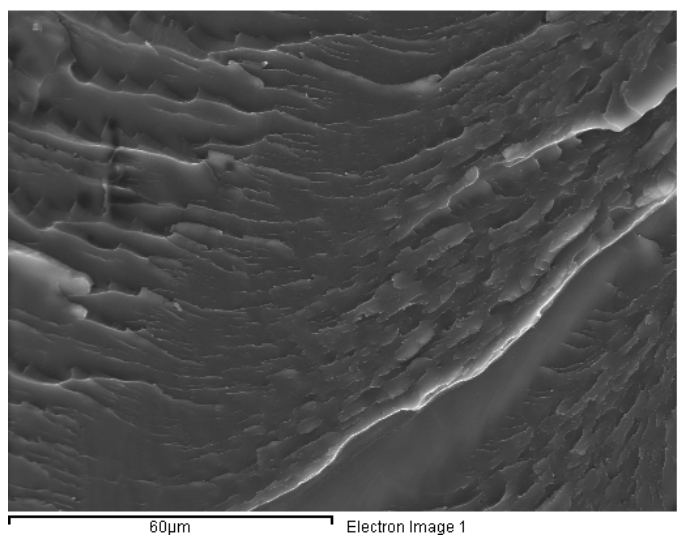

(d)

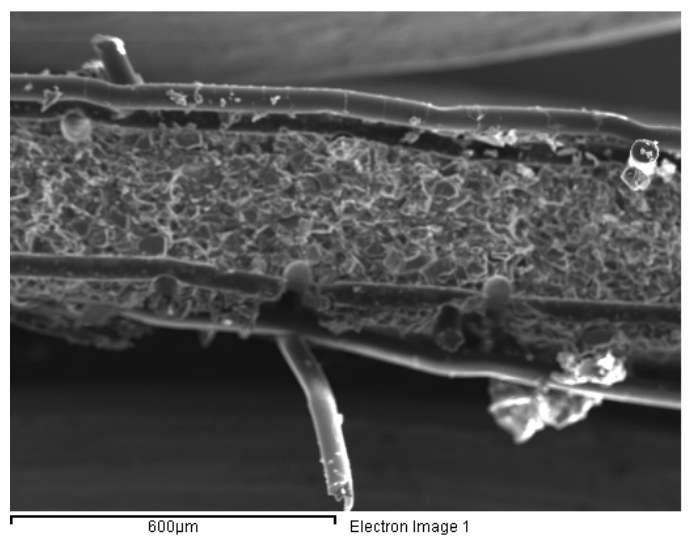

(f)

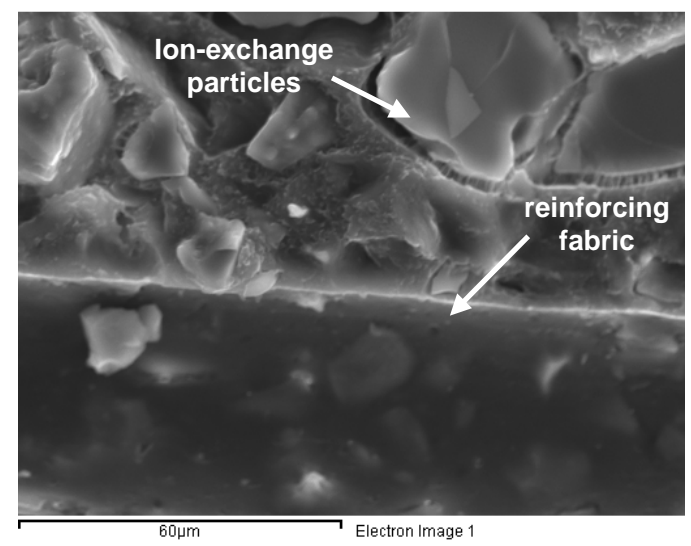

Figure 2. SEM micrographs of different membranes: (a) surface and (b) cross section of Nafion 117 obtained at $60 \mu \mathrm{m}$, (c) surface and (d) cross section of HDX 100 obtained at $600 \mu \mathrm{m}$ and, (e) surface and (f) cross section of HDX 100 obtained at $60 \mu \mathrm{m}$. 
(a)

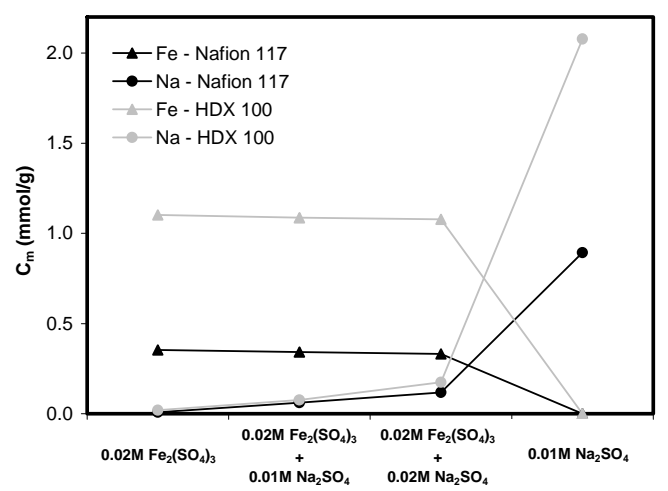

(b)

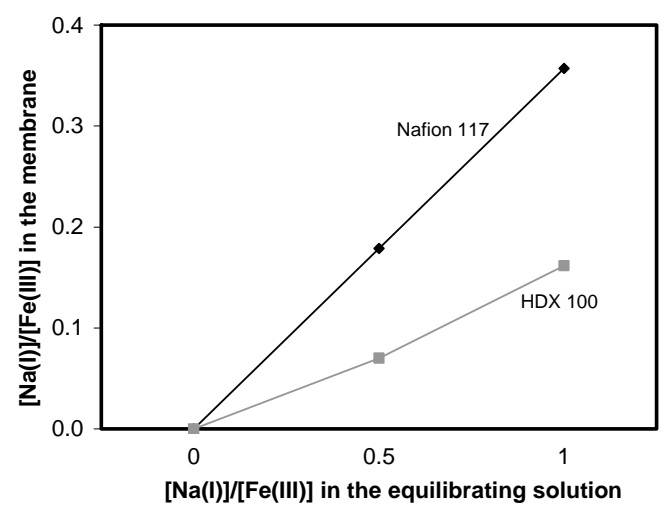

Fig. 3. (a) Concentration of iron and sodium equilibrated in the membrane phase as a function of the electrolyte composition and (b) variation of the $[\mathrm{Na}(\mathrm{I})] /[\mathrm{Fe}(\mathrm{III})]$ ratio in the membrane phase with the $[\mathrm{Na}(\mathrm{I})] /[\mathrm{Fe}(\mathrm{III})]$ ratio in the electrolyte solution for the Nafion 117 and HDX 100 membrane. 
(a)

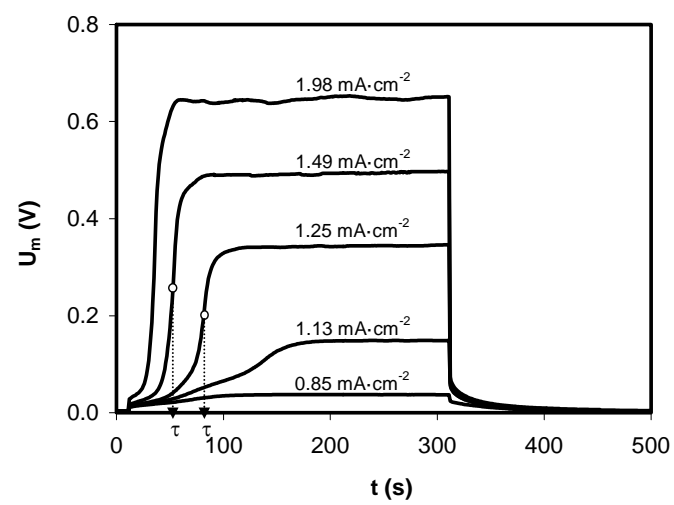

(b)

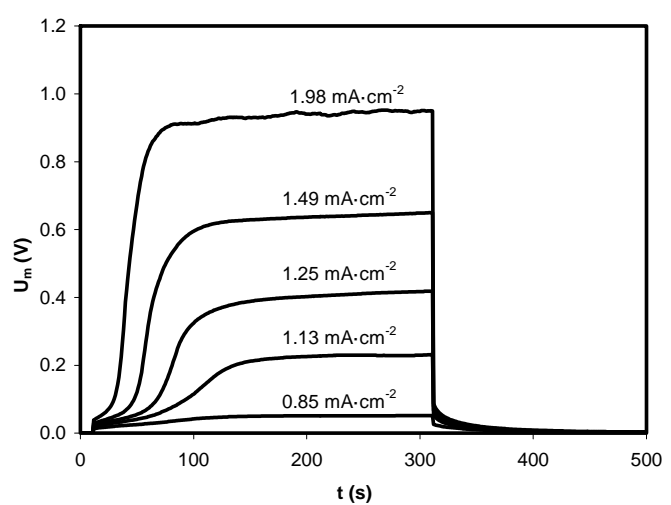

Fig. 4. Chronopotentiometric response obtained with $0.01 \mathrm{M} \mathrm{Na}_{2} \mathrm{SO}_{4}$ solutions with (a) Nafion 117 and (b) HDX 100 membrane. 
(a)

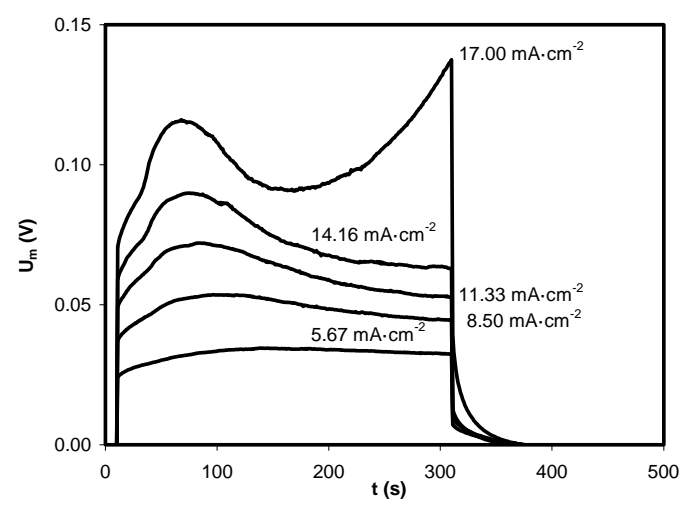

(c)

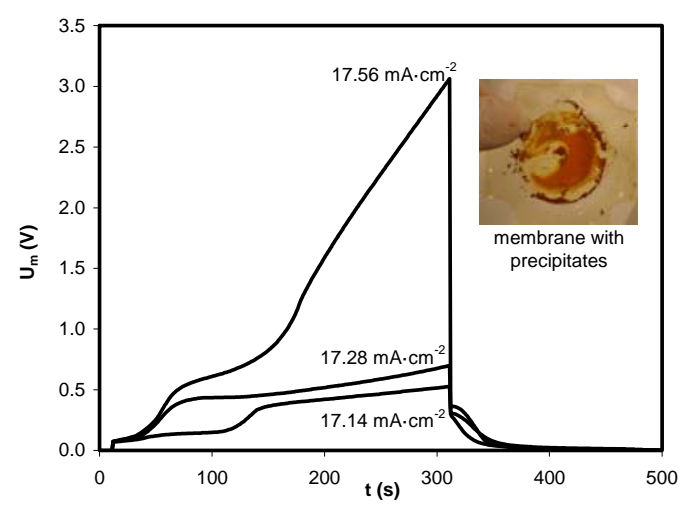

(b)

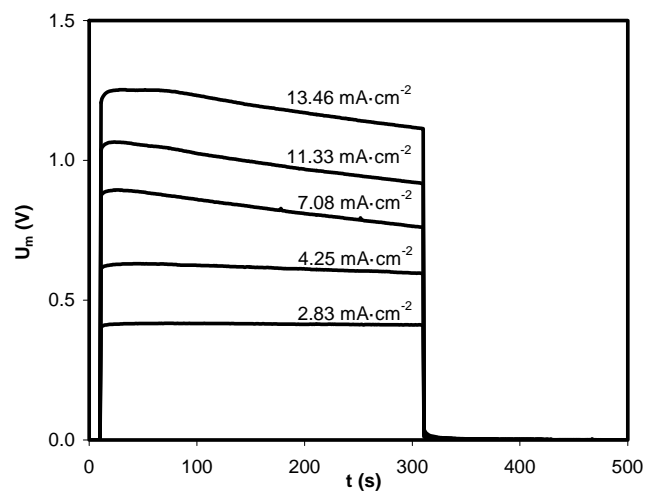

(d)

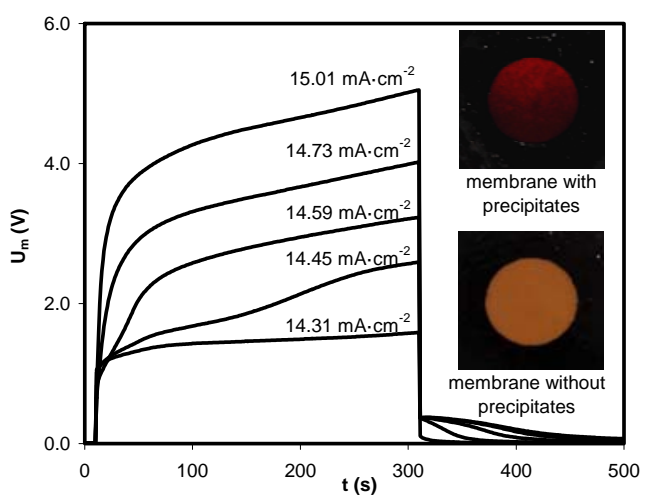

Fig. 5. Chronopotentiometric response obtained with $0.02 \mathrm{M} \mathrm{Fe}_{2}\left(\mathrm{SO}_{4}\right)_{3}$ solutions in the underlimiting range of currents for (a) Nafion 117 and (b) HDX 100; and in the overlimiting range of currents for (c) Nafion 117 and (d) HDX 100. 
(a)

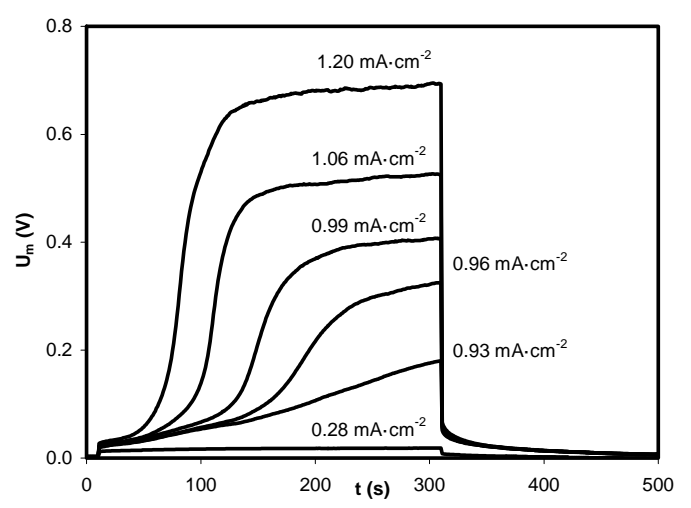

(b)

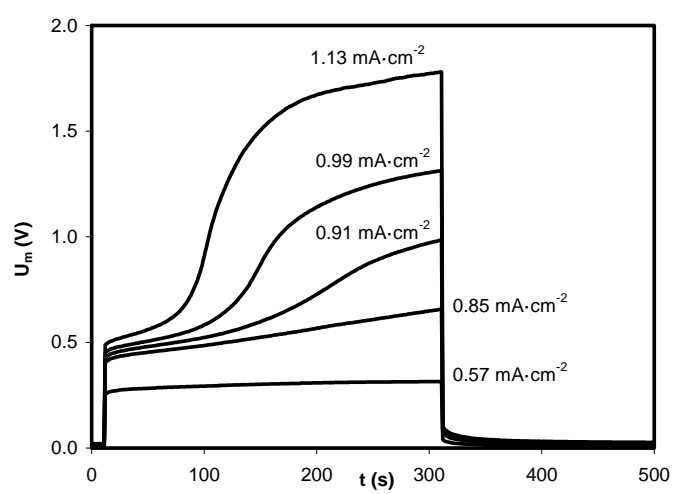

Fig. 6. Chronopotentiometric response obtained with $0.001 \mathrm{M} \mathrm{Fe}_{2}\left(\mathrm{SO}_{4}\right)_{3}$ solutions with (a) Nafion 117 and (b) HDX 100 membrane. 
(a)

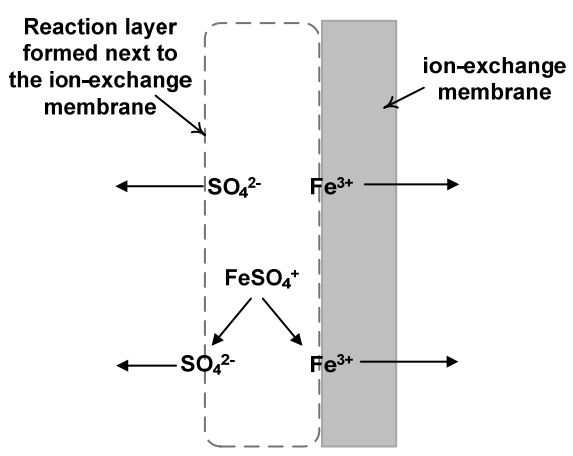

(c) (b)

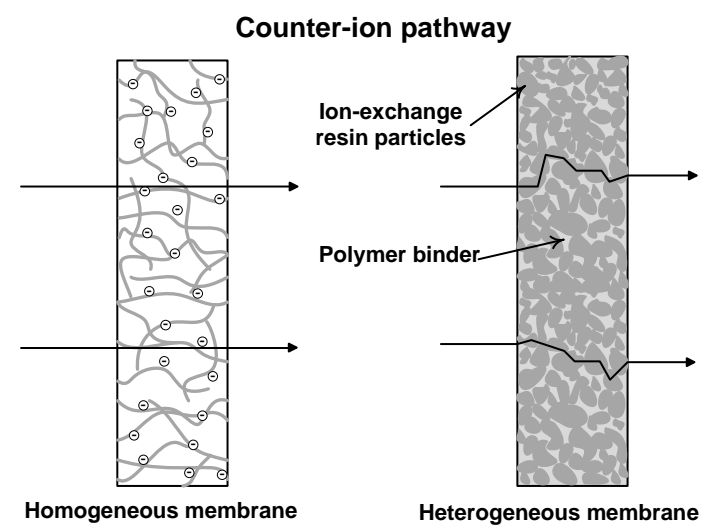

(d)

(e)
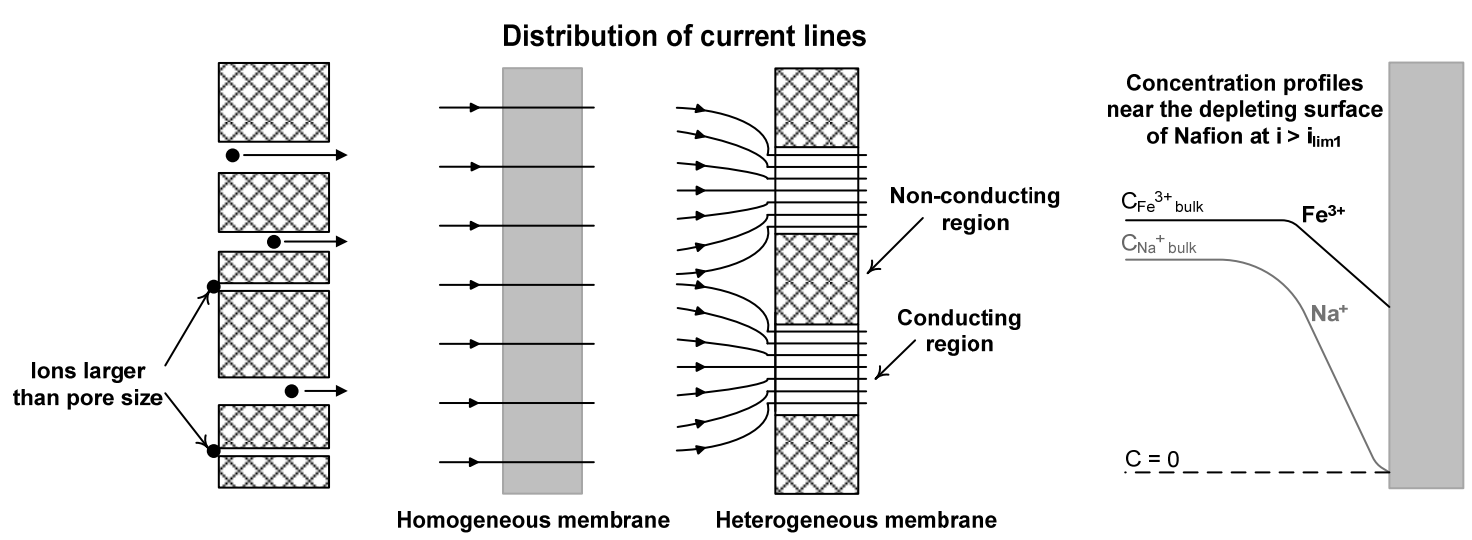

Fig. 7. Schematic representation of several transport processes taking place through the ion-exchange membranes. (a) Dissociation of $\mathrm{FeSO}_{4}{ }^{+}$ions at the anodic boundary layer of the membranes occurring when a certain polarization level is reached, (b) comparison between the counter-ion pathway through homogeneous and heterogeneous membranes (adapted from [29]), (c) blocking of membrane pores of smaller size than the electrolyte counter-ions (adapted from [19]), (d) distribution of current lines near the surface of homogeneous and heterogeneous membranes (adapted from [14]), and (e) concentration profiles of $\mathrm{Fe}^{3+}$ and $\mathrm{Na}^{+}$ions near the anodic side of the Nafion membrane under the application of currents higher than $i_{\lim 1}$. 
(a)

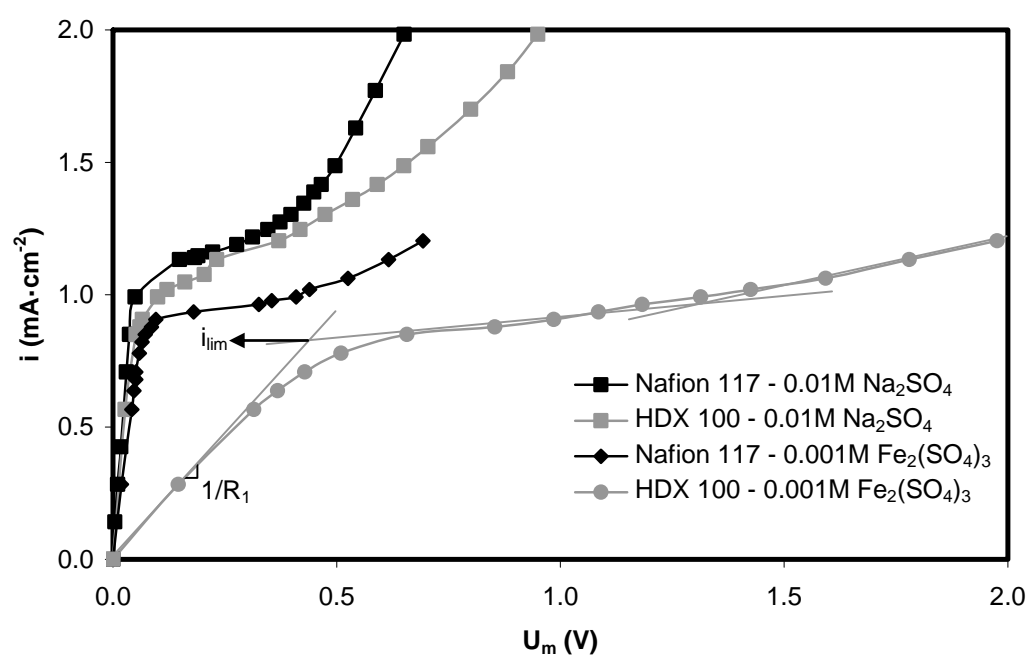

(b)

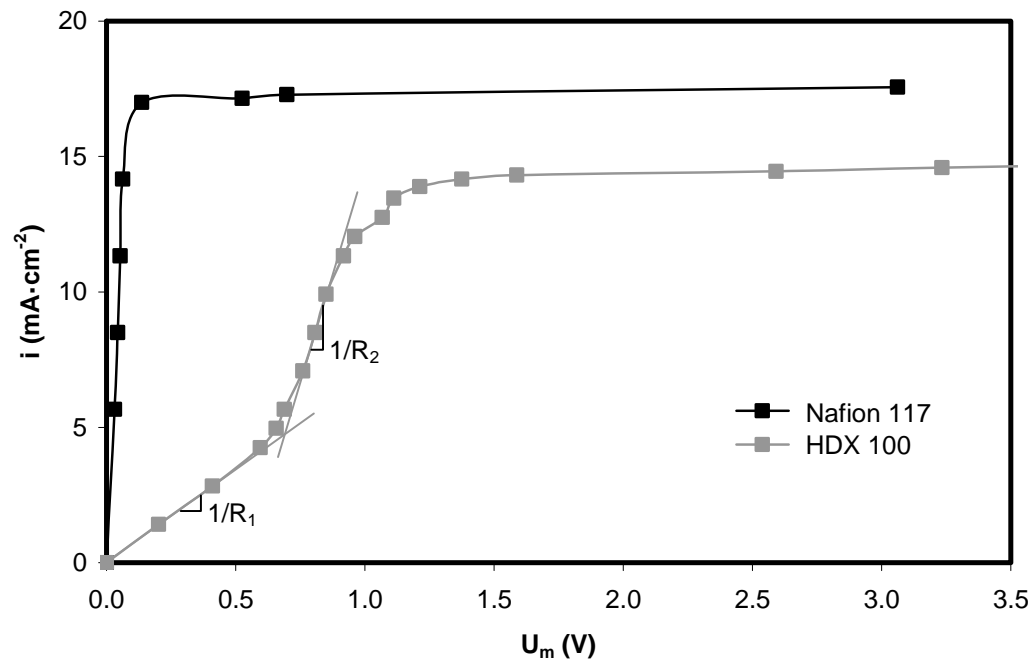

Fig. 8. Current-voltage curves obtained with the homogeneous Nafion 117 and heterogeneous HDX 100 membrane (a) with systems of diluted single salt solutions of $\mathrm{Na}_{2} \mathrm{SO}_{4}$ and $\mathrm{Fe}_{2}\left(\mathrm{SO}_{4}\right)_{3}$ and (b) with systems of $0.02 \mathrm{M} \mathrm{Fe}_{2}\left(\mathrm{SO}_{4}\right)_{3}$ solutions. 
(a)

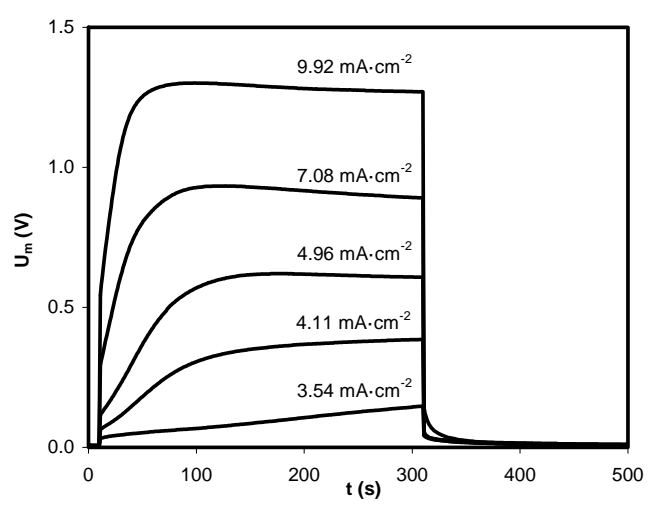

(c)

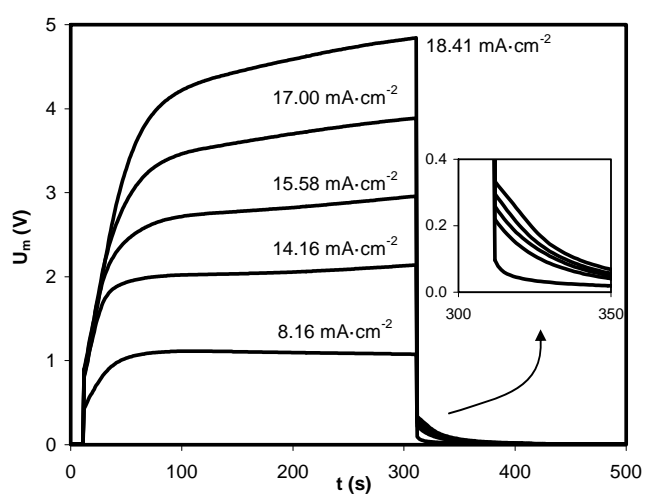

(b)

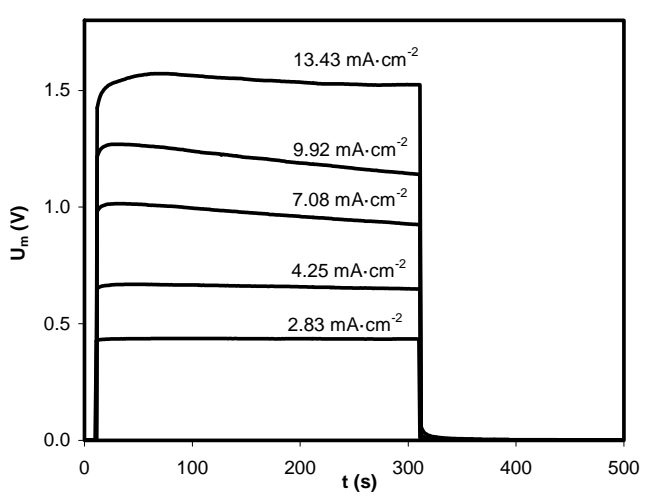

(d)

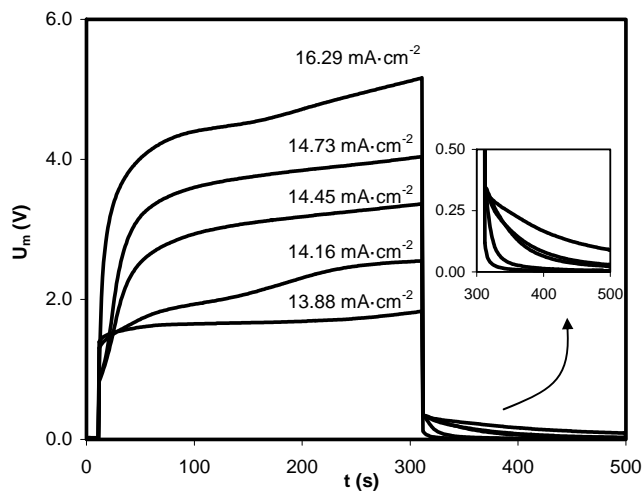

Figure 9. Chronopotentiometric response obtained with multicomponent salt mixtures of $0.02 \mathrm{M} \mathrm{Fe}_{2}\left(\mathrm{SO}_{4}\right)_{3}$ and $0.01 \mathrm{M} \mathrm{Na}_{2} \mathrm{SO}_{4}$ obtained at low and intermediate values of current (a) for the Nafion 117 membrane and (b) for the HDX 100 membrane; and at high values of current (c) for the Nafion 117 membrane and (d) for the HDX 100 membrane. 


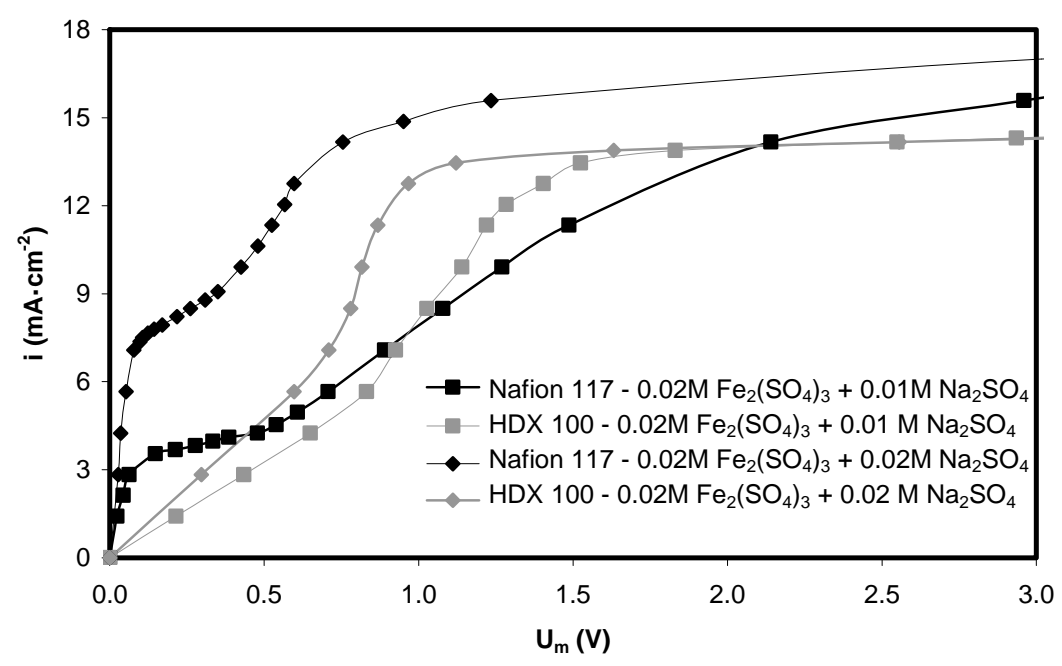

Fig. 10. Current-voltage curves obtained for the homogeneous Nafion 117 and heterogeneous HDX 100 membranes with multicomponent salt mixtures of $\mathrm{Fe}_{2}\left(\mathrm{SO}_{4}\right)_{3}$ and $\mathrm{Na}_{2} \mathrm{SO}_{4}$. 